\title{
Uncertainty in Damage Assessment and Remaining Life Prediction of Engineering Materials Used In Petrochemical Industry
}

\section{Ray $A^{1 *}{ }^{1 *}$ Roy $N^{1}$, Raj $A^{2}$, Matwa $M^{3}$, Davuluri $A^{3}$, Kumari $A^{4}$, Kumar $P^{5}$, Mundhada $D^{6}$, Kaushal $V^{3}$ and Roy BN}

${ }^{1}$ Materials Science and Technology Division, CSIR-NML(National Metallurgical Laboratory) PO-Burmamines, Jamshedpur-831007, India

${ }^{2}$ R.V.S. College of Engineering and Technology, Jamshedpur-831012, India

${ }^{3}$ Indian Institute of Technology, Kharagpur-721302, India

4Indian Institute of Technology, (BHU) Varanasi-221005, India

${ }^{5}$ National Institute of Technology, Rourkela-769008, India

${ }^{6}$ National Institute of Technology, Warangal-506004, India

${ }^{7}$ Bihar Institute of Technology, Sindri-828123, India

\begin{abstract}
In this paper creep damage assessment of about 11 years' service exposed HP-40 grade of steel used in hydrogen reformer of a petrochemical industry has been carried out in terms of a discontinuous Markov process. Experimentally determined conventional creep data under identical testing condition were used in the present investigation. Scatter and damage accumulation due to creep deformation were evaluated through microstructural assessment using light optical microscope and scanning electron microscope. Quantification of creep damage was made from replicated creep data in terms of two damage parameters $A$ and $A^{*}$. Statistical analysis of void area fraction has been carried out extensively for the both top and bottom portions of the reformer tube at $870^{\circ} \mathrm{C}$ in the stress range of 52-68 MPa. In addition, the proposed probabilistic model has been compared with the Kachanav's Continuum Damage Mechanics (CDM) model. Both the approaches displayed quantitative experimental support. A residual life of $\rangle 10$ years is estimated at $870^{\circ} \mathrm{C} /$ operating stress. For 55 years' service exposed Catalytic Cold Cracking (CCU) reactor vessel and Feed Processing Unit (FPU) distillation column materials of a petrochemical industry remnant life assessment studies were estimated by incorporating the uncertainty involved in calculation of LMP (Larson Miller Parameter) values and from extrapolation of stress vs. LMP plot. Variability of normalized creep damage for reactor and column materials is well approximated with the aid of Weibull distribution. As expected, it is observed that the distributions shift towards the higher range of damage with increase in service exposure time.
\end{abstract}

Keywords: Conventional creep test; Void fraction; Damage assessment; Fractography; Microstructural assessment; Statistical analysis; CDM model; Larson-Miller parameter

\section{Introduction}

HK and HP series are centrifugally cast austenitic stainless steels, widely used as for reformer tubes in the petrochemical industry for ammonia, methanol and hydrogen plants. And they operate above $900^{\circ} \mathrm{C}$. Amongst them $\mathrm{HP} 40 \mathrm{Nb}$ and micro alloyed is more popularly used around the world for such application. The main criteria for their selection are their high creep strength at and above $900^{\circ} \mathrm{C}[1-$ 3]. But in remaining life estimation studies of these materials, scatter characteristic of service exposed material is not taken into account for damage.

Under service exposure condition, reformer tubes have been subjected to carbonization, oxidation, overheating, stress corrosion cracking, sulfidation and thermal cycling. Overheating of the tubes leads to early creep damage and embrittlement [3-7]. Premature failure of these tubes can take place due to service ageing which is the major cause for rupture Traditional stainless steel application for vertical reformer tubes has been gradually replaced or substituted by centrifugally cast HK40 alloys and subsequently by HP modified alloys. Even after these advancements, many reformers fail during service within a period of 3 to $15 \mathrm{yrs}$, though their designed performance is specified as $11.4 \mathrm{yrs}$. On the other hand, it is noteworthy that despite most of these tubes have a specific design life of 10-15 yrs, literature survey has revealed that they can have a significant remnant life beyond their specified design life [2]. This is estimated by carrying out RLA (residual life assessment) studies performed at progressive intervals during a well-planned shut down, both by non-destructive evaluation technique and also by destructive tests like accelerated creep or stress rupture tests above the operating hoop stress level of the tubes. Balance or residual life of the tubes can then be estimated by using LMP (Larson-Miller Parameter) equation [5].

Some past observation of remnant life on service exposed materials has been reported in literature [2,4-7]. But in these studies scatter characteristic of service exposed material is not taken into account for damage/ remaining life assessment. The Weibull distribution function [8,9] is commonly used to model the statistical behaviour of experimental results to provide a reasonable fit to the probability distributions of life times (time to rupture) obtained from such tests. This explains to some extent the variability in life time. However the probability distribution of damage as it evolves during the test cannot be reasonably represented by Weibull distribution in many cases. This is because it looks only at two limiting states, viz., and the initial state when material is virgin and the final state when the material has failed (ruptured). This imposes severe limitations as it cannot predict any

*Corresponding author: Dr. Ashok Kumar Ray, Chief Scientist and GL/ Head of Materials Testing and Evaluation Section (Creep, Fatigue \& Fracture), Materials Science and Technology Division, CSIR-NML(National Metallurgical Laboratory) PO-Burmamines, Jamshedpur-831007, India, Fax: 91-657-2345213; E-mail: asokroy@nmlindia.org

Received June 06, 2014; Accepted July 22, 2014; Published July 30, 2014

Citation: Ray AK, Roy N, Raj A, Matwa M, Davuluri A, et al. (2014) Uncertainty in Damage Assessment and Remaining Life Prediction of Engineering Materials Used In Petrochemical Industry. J Pet Environ Biotechnol 5: 181. doi:10.4172/21577463.1000181

Copyright: () 2014 Ray AK, et al. This is an open-access article distributed under the terms of the Creative Commons Attribution License, which permits unrestricted use, distribution, and reproduction in any medium, provided the original author and source are credited. 
intermediate states of damage accumulation. Bogdanoff and Krieger [10] and Ganesan [11] have developed an evolutionary probabilistic model for fatigue life time prediction. This gives the evolution of the probability distribution as a function of number of cycles or time.

Most structural materials are developed by optimizing microstructure to deliver a specified short term mechanical performance. During high temperature service, this carefully tailored microstructure may progressively degrade with often unexpected consequences for long term creep performance. An effective life assessment strategy not only requires a robust creep mechanics framework but also a quantitative description of the various microstructural damage mechanisms. Therefore it is essential to quantify the microstructural damage parameters that have a significant influence on creep behaviour. Nucleation and growth of cavities or voids at grain boundaries or even at precipitate/matrix interface are responsible for creep rupture of the tubes. Quantification of creep damage was made from replicated creep data in terms of two damage parameters $\mathrm{A}$ and $\mathrm{A}^{*}$. Nucleation of cavities at grain boundaries \& precipitate matrix interface and their subsequent growth \& coalescence are thought to be the mechanisms for its creep rupture. A suitable methodology of characterizing creep damage evolution and quantitative metallography evaluation of creep cavitation has not so far been studied.

In the present work, Bogdanoff model (B-model) based on Markov process [12] and Kachanov [13] CDM model (K-model) have been used to predict creep damage evolution. Monte Carlo Simulation has been carried out to predict the associated scatter in damage evolution under identical test conditions. The model(s) have been applied to creep strain accumulation data of 11 years' service exposed reformer tube (both top and bottom portion) made up of HP40 grade of steel in a petrochemical industry, for different stress-temperature conditions. Also a quantitative metallography study on the extent of creep cavitation and statistical analysis of void area fraction has been carried out extensively for both top and bottom portion of the reformer tube at $870^{\circ} \mathrm{C}$ in the stress range of 50-68 MPa. The method of quantitative metallography evaluation of voids on crept samples of this material has already been reported elsewhere [14].

\section{Material and Experimental Procedure}

The tube material used in this study is made of HP40 grade of steel which is about 11 years' service exposed and operating at $870^{\circ} \mathrm{C}$, though the designed operating temperature of the tube specified by the plant is $920^{\circ} \mathrm{C}$. The tubing material is equivalent to $25 \mathrm{Cr} 35 \mathrm{Ni} 1 \mathrm{Nb} 0.2 \mathrm{Ti} 0.01 \mathrm{Mo}$. Room and high temperature $\left(850^{\circ} \mathrm{C}, 870^{\circ} \mathrm{C}\right.$ and $\left.890^{\circ} \mathrm{C}\right)$ tensile tests of the material were carried out as per ASTM-8M standard, which enables one to fix the operating stress level during creep tests so that rupture occurs reasonably within a stipulated time frame. Conventional creep tests of the tubes at $870^{\circ} \mathrm{C}$ were conducted as per ASTM E
139/83 specification in single point ATS Creep Testing Machines (2T capacity), equipped with a three zone split furnace and maintaining zonal temperature within $\pm 2^{\circ} \mathrm{C}$ with a high precision controller. Strain measurements were made as per ASTM E 139/83 standard procedure, with LVDT (Linear Variable Displacement Transformer) attachment in the bottom pull rod, outside the furnace but connected to both the extensometers fixed at the top as well as bottom portion of the specimen gauge length, well within the furnace of the ATS creep testing machine. Round bar cylindrical solid specimens having a gauge diameter of 5.0 $\mathrm{mm}$ and a gauge length of $28.47 \mathrm{~mm}$ were chosen both for tensile as well as creep tests [14]. Creep specimens were loaded at 50-68 MPa / $870^{\circ} \mathrm{C}$. The operating hoop stress $\sigma_{\mathrm{h}}(13.46 \mathrm{MPa})$, was evaluated using the following formula:

$$
\sigma_{h}=P D / 2 t
$$

Where $\mathrm{P}$ is the operating pressure in $\mathrm{MPa}, \mathrm{D}$ is the mean diameter in $\mathrm{mm}$ and $\mathrm{t}$ is the thickness of the tube in $\mathrm{mm}$. The stress rupture data have been plotted in terms of stress versus LMP (Larson-Miller parameter):

$$
\mathrm{LMP}=\mathrm{T}\left(\mathrm{C}+\log \mathrm{t}_{\mathrm{r}}\right)
$$

Where $\mathrm{T}$ is the absolute temperature in $\mathrm{K}, \mathrm{t}_{\mathrm{r}}$ is the rupture time in hours and $\mathrm{C}$ is a constant generally taken as 20 . For this grade of steel two values of $C(C=15$ and $C=20)$ were considered (Table 1$)$ for balance or remaining life prediction as the major alloying element in this grade of steel is $\mathrm{Ni}$.

From Equation (2) rupture time can be specified as

$$
\mathrm{t}_{\mathrm{r}}=10^{\frac{L M P}{T}-C}
$$

In case of CCU reactor and FPU distillation column materials, accelerated creep rupture tests were carried out in the temperature range of $515-520^{\circ} \mathrm{C}$ and in the stress range of $60-120 \mathrm{MPa}$. The stress levels above the operating stress at each temperature were selected in such a way as to obtain rupture within a reasonable span of time. In general, creep rupture damage $(\omega)$ is considered as the ratio of cumulative operating time and total operating time [15].

$$
\omega=\frac{t}{t+t_{r}}
$$

Creep rupture damage $(\omega)$ has been evaluated in terms of LarsonMiller parameter with a functional relation is derived as follows [15]:

$$
\omega=a_{0}+a_{1} L M P+a_{2} L M P^{2}
$$

\begin{tabular}{|c|c|c|c|c|c|c|}
\hline $\begin{array}{l}\text { Component (service } \\
\text { exposed) }\end{array}$ & $\begin{array}{l}\text { Hoop Stress, } \\
\mathrm{MPa}\end{array}$ & Temp., ${ }^{\circ} \mathrm{C}$ & $\begin{array}{c}\text { C } \\
\text { (LMP constant) }\end{array}$ & $\begin{array}{c}\text { LMP of Service exposed } \\
\text { material }\end{array}$ & Life $\left(t_{r}\right)$, yrs & $\begin{array}{l}\text { Remaining Life } \\
(\mathrm{RL})^{\star} \text {, yrs }\end{array}$ \\
\hline \multirow{4}{*}{ Reformer tube (Top) } & \multirow{8}{*}{13.46} & \multirow{2}{*}{870} & 20 & 30800 & $>10$ & $>10$ \\
\hline & & & 15 & 24100 & $>10$ & $>10$ \\
\hline & & \multirow{2}{*}{920} & 20 & 30800 & $>10$ & $>10$ \\
\hline & & & 15 & 24100 & 18 & 7 \\
\hline \multirow{4}{*}{ Reformer tube (Bottom) } & & \multirow{2}{*}{870} & 20 & 30600 & $>10$ & $>10$ \\
\hline & & & 15 & 24100 & $>10$ & $>10$ \\
\hline & & \multirow{2}{*}{920} & 20 & 30600 & $>10$ & $>10$ \\
\hline & & & 15 & 24050 & 17 & 6 \\
\hline
\end{tabular}

This relation is true only when one could generate a large number of experimental accelerated creep rupture data with specimens removed during large number of plant shut downs i.e. with various years of

${ }^{*} R L=t_{r}-11$ (service exposure in yrs)

Table 1: Remaining life at different temperature with varying C (LMP constant) value. 
service exposure [15] as in the case of 55 years' service expose CCU reactor and FPU distillation column materials. The column is made of mild steel conforming to ASTM a $285 \mathrm{Gr}$. C and the reactor vessel conforming to ASTM a $201 \mathrm{Gr}$. A.

To reduce error in damage calculation, experimental creep damage was normalized by predicted creep damage (Equation (5)). Variability of normalized creep damage can be well approximated with the aid of Weibull distribution [16]. Creep damage $(\omega)$ in terms of probability of failure and LMP can be expressed as:

$$
\omega=a\left(a_{0}+a_{1} \mathrm{LMP}+a_{2} \mathrm{LMP}^{2}\right)\left(\left(-\ln \left(1-P_{f}\right)\right)^{\frac{1}{b}}\right.
$$

Where $\mathrm{a}, \mathrm{b}$ are Weibull parameter and $\mathrm{P}_{\mathrm{f}}$ is probability of failure.

In the present study, a set of four specimens were tested under identical condition to examine the statistical creep behaviour. Scatter in voids was quantified from Light Optical Microscopy (LOM), SEM (Scanning Electron Microscope) equipped with image analyzing technique and EDX (Energy Dispersive Xray Spectroscopy) analyser. Identification of various elements was carried out with EDX. A detailed analysis of this technique and its interpretation is given elsewhere [14]. Fractographic features were recorded and studied for all the crept samples in the SEM. One half of the creep ruptured pieces were cut longitudinally along the mid plane, mirror polished

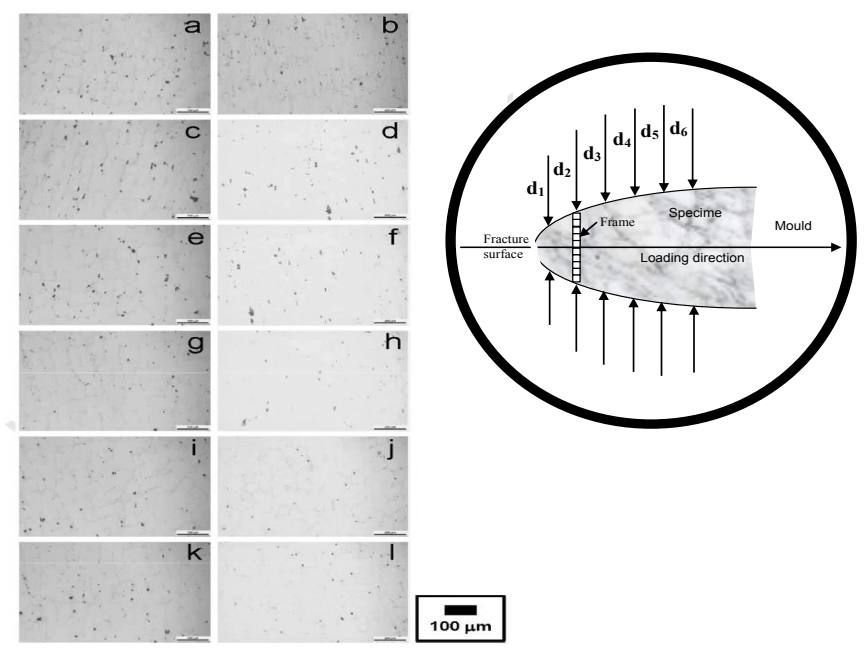

Figure 1: Extent of creep cavity at various stresses and strains (a,c,e,g,i,k) - $50 \mathrm{MPa}$ and $(\mathrm{b}, \mathrm{d}, \mathrm{f}, \mathrm{h}, \mathrm{j}, \mathrm{l})-68 \mathrm{MPa}$ for the top tube. True strain at (a) 1.187,(c)0.897,(e) 0.626, (g) 0.525,(i) 0.398 and (k) 0.359.(b) 0.781 ,(d) 0.652 ,(f) 0.565 ,(h) 0.40, (j) 0.244 and (I) 0.149 [14].

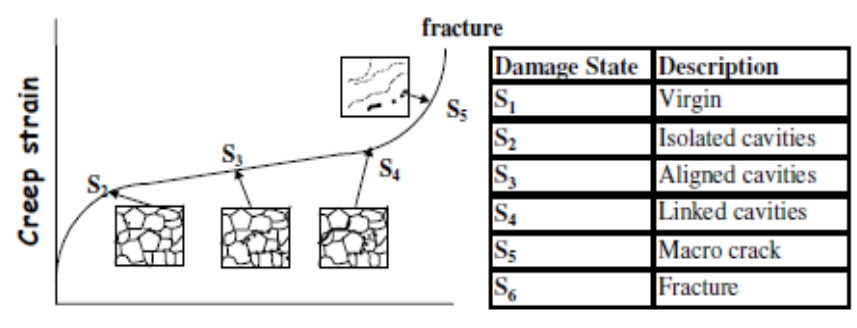

Exposure time

Figure 2: A schematic representation of the nature of damage evolution in material subjected to creep loading and the phases used to represent the same. through conventional metallographic technique to reveal creep cavity. Fractography was carried out on the other half of the fractured specimens. Quantification of damage in terms of voids was made both at perpendicular as well as parallel directions to the loading axis of the gage length of the specimens [14]. These observations were made on a plane which corresponds to the mid-section of the specimen diameter at different distances from the ruptured surface. Ten optical images at diametric locations were recorded digitally at 400X. Only after appropriate grey-thresholding, these optical images had been analyzed with a view to obtaining the void area as a function of true strain after creep rupture.

It is well established that true stain is a function of the diameter (D) of the specimen at the specific transverse plane and is represented by [17]:

$$
\varepsilon=2 \operatorname{Ln}\left(\frac{D_{0}}{D}\right)
$$

Where $\mathrm{D}$ is the measured diameter and $\mathrm{D}_{0}$ is the original diameter of the specimen. For the purpose of maintaining uniformity, void area was normalized with respect to true strain which has been measured from crept and ruptured specimens as shown in Figure 1.

\section{Creep Damage Modelling for Service Exposed Reformer Tubes}

In polycrystalline metals undergoing creep at high temperatures, failure occurs mainly by the nucleation and growth of microscopic cavities on the grain boundaries. Cavitation is one of the most common forms of creep damage. This has been correlated with creep stain accumulation by direct metallographic examination of power plant components exposed to creep. Figure 2 shows a schematic representation of the nature and distribution of cavities during various stages of creep strain accumulation in a component. The process truly consists of both nucleation and growth, the former is probabilistic whereas the latter is deterministic. A probabilistic mechanism is best represented as a discrete process whereas growth is continuous by nature. Predictive models based on deterministic approach consider constrained growth of cavities as the principal mechanism. Such models assume presence of extremely fine cavities as pre-existing nuclei. Their initial sizes are too small to account for any loss of effective load bearing cross section area of the component. If at all it contributes it is likely to affect the initial strength of the material and its effect would show up as scatter in the experimental creep strain time plot. Nevertheless with this assumption deterministic model does describe many of the features of the creep curves described above. Following the same analogy it is possible to build up a model entirely based on probabilistic approach assuming creep damage accumulation as a discrete process.

\section{Deterministic approach: CDM model for creep damage of service exposed reformer tubes}

The work of Kachanov [13] and Rabotnov [18] is of considerable relevance to evaluate material degradation due to creep. They assumed that during creep, damage accumulation progressively reduces the effective load bearing cross sectional area of a specimen from an initially intact condition to a complete loss when rupture occurs. Kachanov [13] CDM model (K-model) has been used to estimate creep damage. The model is well established and has been applied to analysis of accumulation of creep strain data for 11 years' service exposed reformer tube (both top and bottom portions) for different stresses at $870^{\circ} \mathrm{C}$ in the present investigation.

Strain rate accumulation can be predicted throughout the creep 
life by introducing a generalized damage parameter $(\omega)$. Estimation of damage or loss of continuity is made possible by a set of two coupled equations which fit the limiting conditions i.e., $\omega=0$ at time $t=0$ and $\omega=1$ at time $\mathrm{t}=\mathrm{t}_{\mathrm{r}}$ as:

$$
\begin{aligned}
& \frac{d \varepsilon}{d t}=\frac{A \sigma^{n}}{(1-\omega)^{n}} \\
& \left.\frac{d \omega}{d t} \quad \frac{B \sigma}{(1)}\right)
\end{aligned}
$$

Where, $A, B, n, m$ and $\eta$ are material constants.

Following Cane [19], Equations $(8,9)$ can be integrated for constant stress conditions to give

$$
\omega=1-\left(1-\frac{t}{t_{r}}\right)^{\frac{1}{\lambda}}
$$

Where, $\lambda$ is creep damage tolerance factor [19-22] and is defined as the ratio of strain to failure to the Monkman-Grant constant i.e., $\lambda$ $=\varepsilon_{\mathrm{r}} / \dot{\varepsilon_{m}} t_{r}$ and $\varepsilon_{r}, t_{r}, \dot{\varepsilon_{m}}$ are rupture stain, time to rupture and minimum creep rate respectively. The product $\varepsilon_{m} t_{r} \equiv \varepsilon_{s}$ is the Monkman-Grant constant. $\lambda$ is a significant parameter in assessing the susceptibility of a material to localized cracking at strain concentrations and is also suggested as a better measure of creep ductility [20-22]. Its value for engineering alloys ranges from 1 to about 20 .

Nucleation of cavities being deterministic, the scatter band in damage evaluation under identical test conditions can be easily estimated by carrying out a Monte Carlo Simulation. Similar simulation study was carried out on service exposed austenitic stainless steel [23] and P22 grade of steel [24].

Equation (10) defines a generalized creep damage relationship for estimating creep life fraction consumed at any given time. However, this approach does not consider the scatter that is inherent in any creep test. It would be highly constructive if estimation of remaining life of component could effectively be positioned within the scatter band of creep strain vs time plots.

\section{Stochastic approach: Markov process for creep damage of service exposed reformer tubes}

Nucleation of cavities is one of the principal mechanisms of damage. It considers growth as nucleation on the interface between a pre-existing cavity and the matrix. Growth of cavities/voids is probabilistic. With creep damage accumulation the distance between cavities keep decreasing and ultimately some of these may join together to produce a micro crack. This happens as and when a cavity nucleates in between two adjacent cavities. The process continues leading to the formation of macro cracks. Ultimately the component fails as and when its load bearing cross section area is full of cavities/cracks. In fact Figure 2 gives a schematic representation of the above stages of nucleation and joining of cavities leading to fracture at different levels of strain accumulation. A virgin material passes through each of these stages before failure occurs. The accumulation of micro cracks inside the material is considered as a cumulative damage process. The process of damage accumulation during creep depends only on its current state. Therefore it is possible to simulate this by a Markov chain process.

The Markov process is defined as a stochastic process satisfying the following condition:

$$
\operatorname{Prob}\left[S_{n+1}=j \mid S_{n}=i, S_{n-1}=k, \ldots, S_{o}=1\right]=\operatorname{Prob}\left[S_{n+1}=j \mid S_{n}=i\right]
$$

The indices $i, j, k$, etc. stand for the state number and $\mathrm{S}_{\mathrm{n}}$ stands for $\mathrm{n}^{\text {th }}$ event. Equation (11) says that probability of $S_{n+1}$ being in state $j$ is only affected by the value of $S_{n}$ and the history of state value has no effect on $\mathrm{S}_{\mathrm{n}+1}$.
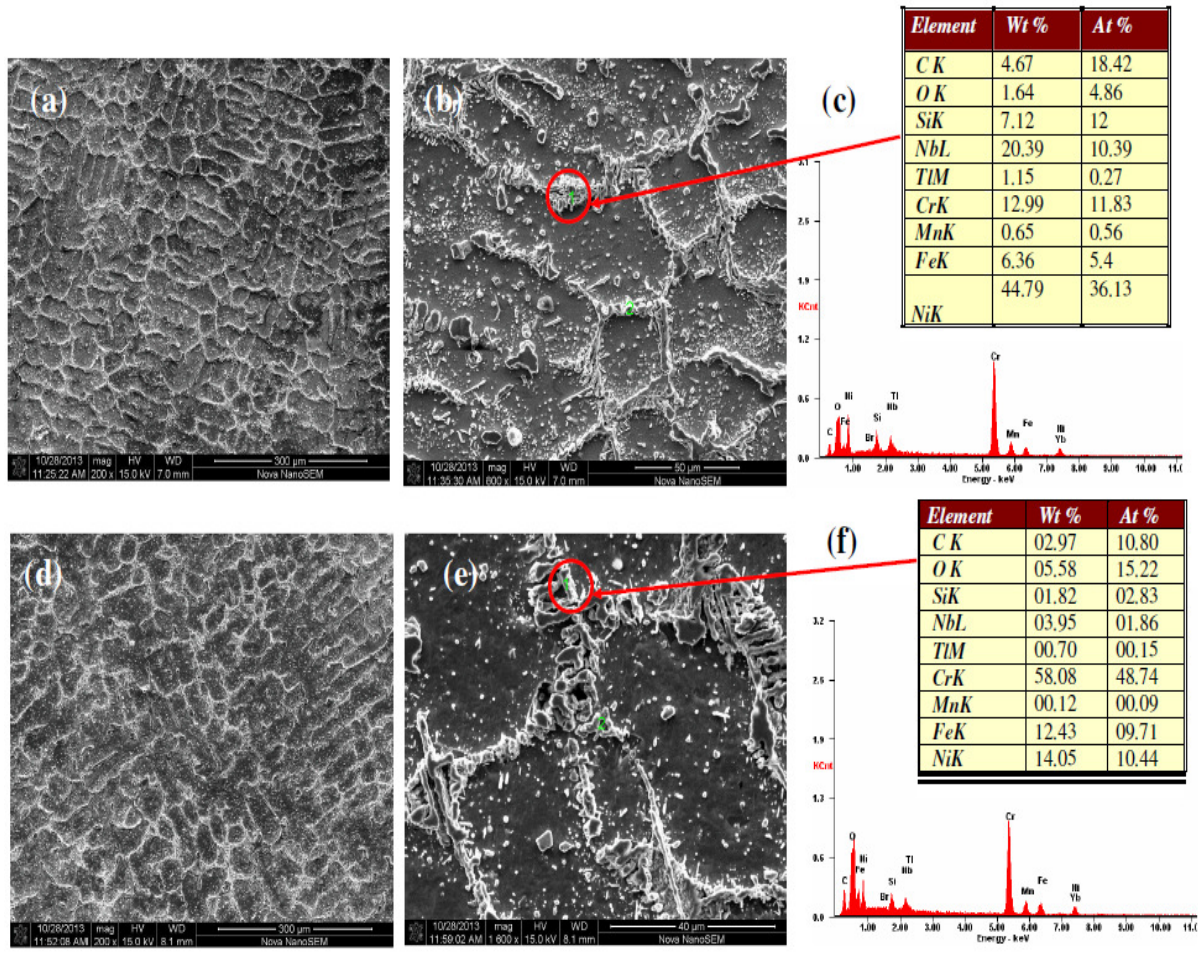

Figure 3: SEM micrograph revealing microstructure of as received top and bottom portions of the reformer tube with EDAX analysis of Cr and Nb rich precipitates. 

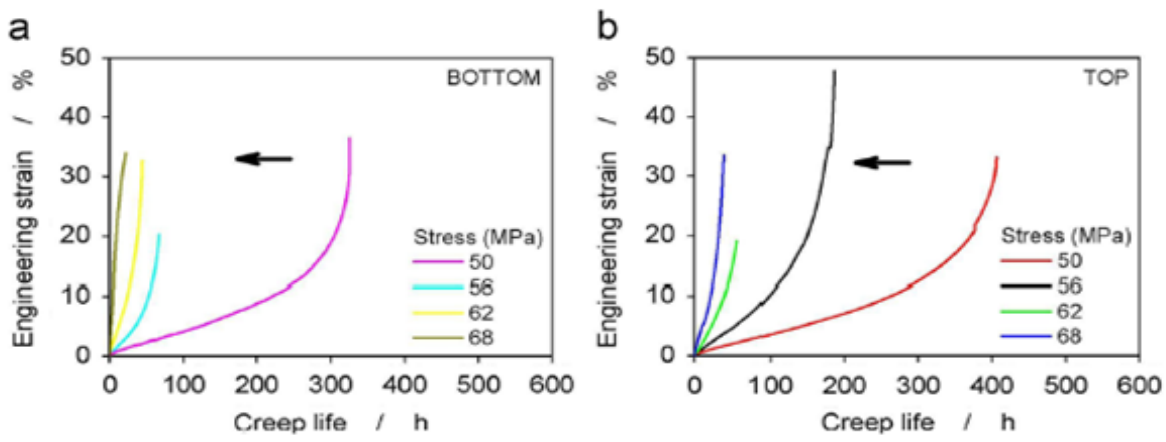

Figure 4(a): Experimental creep curves at four different stress levels for the (a) bottom and (b) top tubes.

State 1 indicates the initial state where there is with no damage and state $\mathbf{b}$ indicating the final damage state (rupture or failure state) or the absorbing state. Leckie et al. [22] have defined the initial distribution of the different damage levels at time $t=0$, by $a(1 \times b)$ row vector $\mathrm{p}_{\mathrm{o}}$ :

$$
\mathrm{p}_{\mathrm{o}}=\left\{\pi_{1}, \ldots \ldots \ldots, \pi_{\mathrm{b}}\right\} \text { and } \sum_{j=1}^{b} \pi_{j}=1
$$

Probability of moving to state 3 and beyond is zero $[23,24]$. Accumulation of creep damage in a material is represented by a transition matrix P, [25]. Please refer to Appendix I for details.

All states in the transition matrix $\mathrm{P}$ are transient, except for state $\mathrm{b}$ (absorbing state). Bogdanoff and Krieger [10] had suggested a simple procedure for estimating these elements to simulate fatigue damage evolution. The same procedure had been used in this work as B - model to predict creep damage evolution as a function of time.

\section{Statistical analysis of creep cavity area for service exposed reformer tubes}

Most of the efforts in the study of creep in steels have focused on experimental research to examine the effect of microstructure on the formation of cavities. Nucleation of cavity is a random process and is strongly dependent upon the local stress-state and strain-state. It has been observed that over various test conditions, for the both top and bottom portion of the reformer tube the normalised void/ creep cavity area fraction, $\mathrm{F}\left(\mathrm{V}_{\mathrm{f}}\right)=\left(\frac{v_{f}}{\varepsilon}\right)$ follows the Weibull distribution.To maintain uniformity, creep cavity area was normalized by respective true strain which has been measured from failed crept specimens as shown in Figure 1 . In terms of true strain $(\varepsilon)$ and cumulative probability of failure $\mathrm{P}_{\mathrm{f}}$ void area fraction $\left(\mathrm{v}_{\mathrm{f}}\right)$ can be probabilistically estimated as [8]:

$$
v_{f}=a \varepsilon\left(\left(-\ln \left(1-P_{f}\right)\right) \frac{1}{b}\right.
$$

Where $\mathrm{a}$ and $\mathrm{b}$ are Weibull parameter.

\section{Results and Discussion}

\section{Microstructure evaluation}

Metallographic examination under SEM is revealed in Figure 3. The as received (uncrept) service-exposed reformer tubes showed that the material did not possess any sign of degradation including decarburization and voids or creep cavitation. Microstructural examination under SEM is revealed in Figure 3a-3d). Both the top as well as bottom portions of the reformer tube revealed columnar type of microstructure (Figure 3a,3d). In general, a columnar type of structure was observed for both the top and bottom portions of the reformer tube. Basically two types of carbides are revealed in the EDX analysis(a) the primary carbide network consisted of chromium-rich $\mathrm{Cr}_{23} \mathrm{C}_{6}$ and (b) niobium-rich carbides as intra-dendritic carbides (light grey ones), with presence of some nickel and silicon in it (Figure 3). Nb rich carbides appear to be coarsened and coagulated. Thus, one could see various morphologies of the precipitates in the intra - dendritic region.

Formation of coarse carbides at dendritic boundaries in the bottom region of the tube as well as gradual disappearance of fine intradendritic precipitates were mainly due to overheating (Figure 3). Due to ageing, these carbides would coarsen and shape themselves as worm $[2,26]$. Presence of significant amount of silicon and nickel at the light grey precipitate confirms that partial conversion of $\mathrm{NbC}$ phase to $\mathrm{Nb}$ $\mathrm{Ni}-\mathrm{Si}$ had occurred [2]. The main damage mechanism for reformer tube is the combination of thermal stresses and internal pressure stresses $[2,26]$. This combination of stresses causes creep damage that typically develops at the inner diameter or just below the internal diameter surface. It was pointed out that test stress was different from service stress because various pressure and wall thickness combination did exist.

\section{Conventional and accelerated creep rupture behaviour of service exposed reformer tubes}

From the hot tensile strength data [14] creep loads at $870^{\circ} \mathrm{C}$ were selected in the range of 50-68 MPa for the service exposed reformer tubes. Hardness and tensile test results [14] when compared with the standard NRIM (National Research Institute for Metals) data of similar grade of steel [27] has clearly established that the material has become softened due to prolonged service exposure, which is also apparent from presence of coarse carbides at dendritic boundaries and disappearance of fine intra dendritic precipitation (Figure 3), at the bottom portion of the tube. Figure 4i represents the experimental creep curves at four different stress levels for the (a) bottom and (b) top tubes. All these curvs clearly depict absence of the primary or Stage I creep region.

The conventional creep curves at $870^{\circ} \mathrm{C}$ (Figure 4ii) and creep strain rate curve (Figure 4iii) of both top as well as bottom portion of the reformer tube corresponding to various stress levels (50 MPa,56 $\mathrm{MPa}, 62 \mathrm{MPa}$ and $68 \mathrm{MPa}$ ) clearly exhibit that there is substantial amount of scatter in creep deformation and creep strain rate curve. It should be noted that no valid service history records were available for the individual tubes; thus, it is possible that the current test samples were machined from tubing which was replaced during an earlier shutdown of the refinery i.e. 5 years ago.

Figure 5 exhibits the fractograph of crept service exposed specimens. The fractured surface (Figure $5 \mathrm{c}, \mathrm{e}, \mathrm{g}, \mathrm{k}, \mathrm{p}$ ) has undergone severe oxidation. It was found to rupture in a relatively brittle manner with $16.4 \%$ elongation for top portion of the tube. Figure $5 \mathrm{a}-5 \mathrm{p}$ is a 

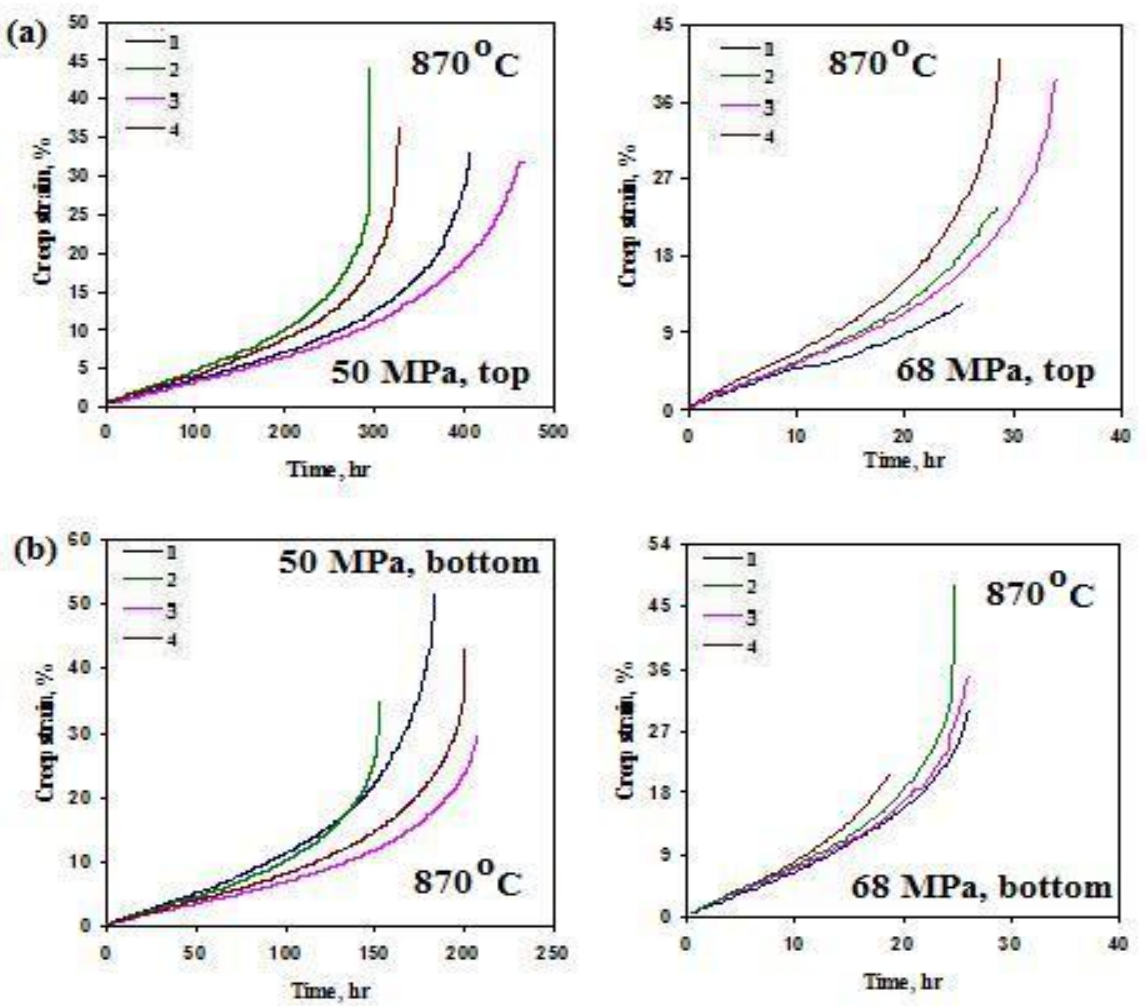

(c)

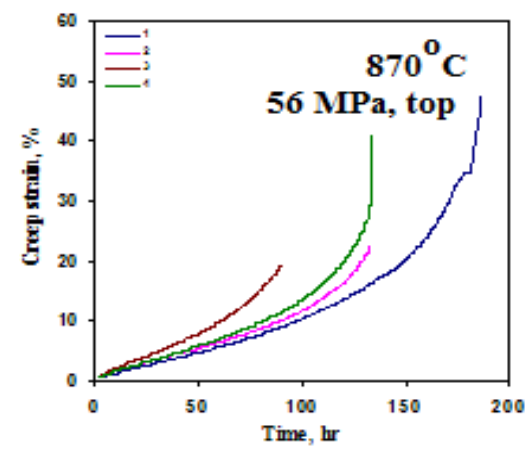

(d)

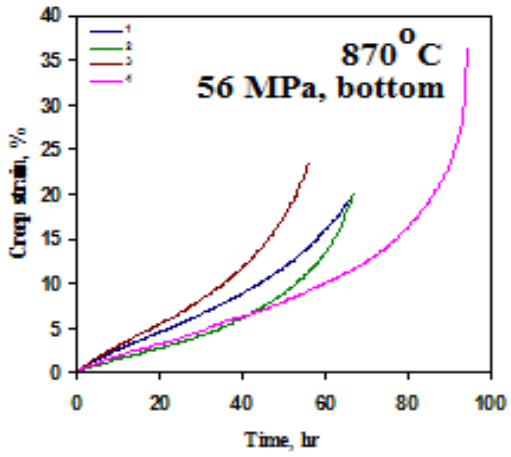

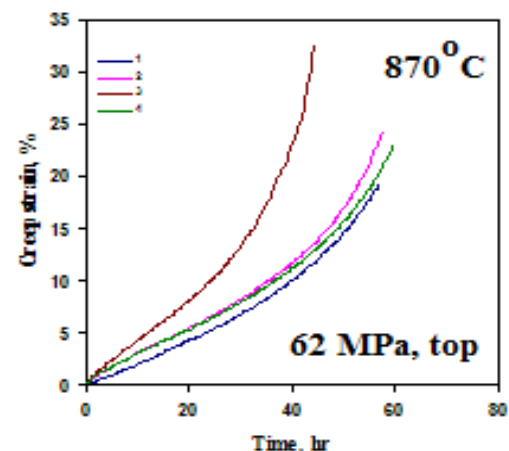

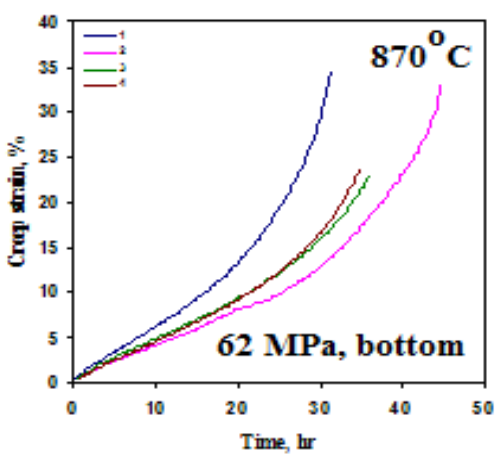

Figure 4(b): Scatter creep curves at $50 \mathrm{MPa}$ and $68 \mathrm{MPa}$ respectively: (a)top and (b) bottom portion of service exposed reformer tube.

general observation of fractographic features of the top as well as the bottom portion of the tube. Bottom portion of the tube fractured with $17 \%$ elongation revealing a quasi-cleavage fracture (Figure $5 c, d, g, k, o, p)$ and a brittle failure with presence of cleavage facet (Figure $5 \mathrm{~g}, \mathrm{o}, \mathrm{p}$ ) respectively. However, in the top section (Figure 5a,b,f,i,j,n) and Figure $5 \mathrm{~d}, \mathrm{~h}, \mathrm{l}$ of the bottom section did reveal ductile dimples. In case of quasi cleavage fracture (Figure $5 \mathrm{c}, \mathrm{d}, \mathrm{g}, \mathrm{k}, \mathrm{o}, \mathrm{p}$ ) possibly, when the specimen finally fractured, the crack propagates into the specimen and remaining 
(e)

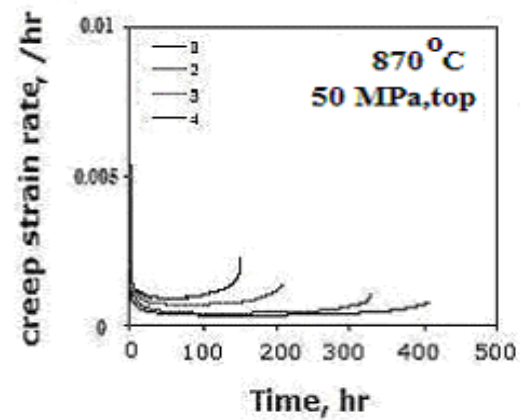

(f)

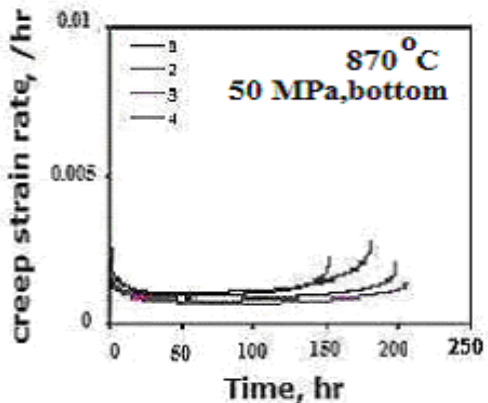

(g)

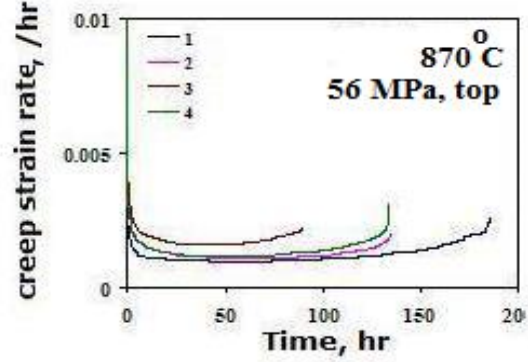

(h)

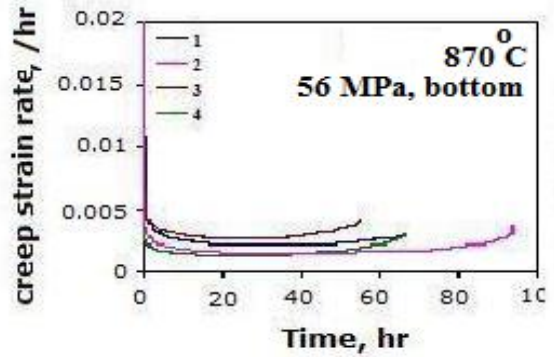

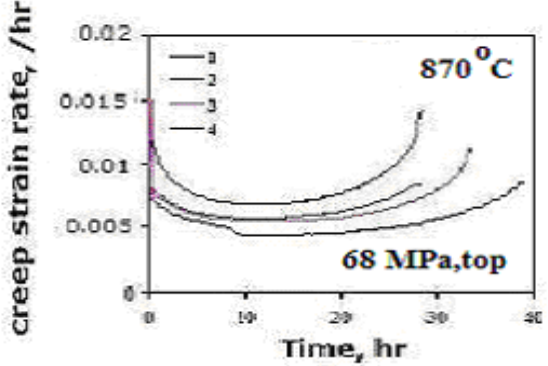
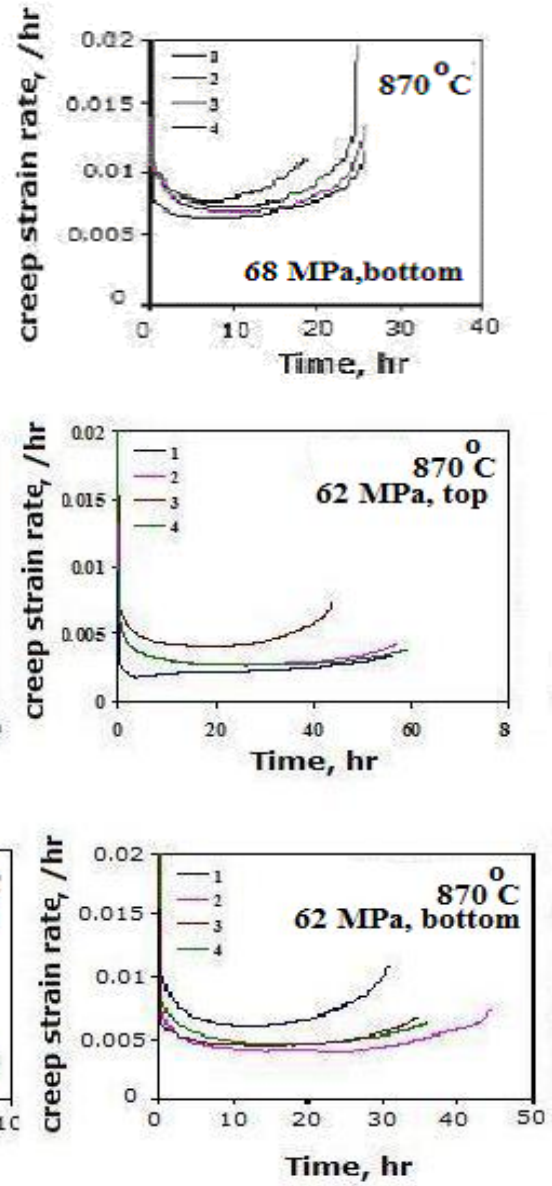

Figure 4(c): Scatter creep strain rate curves at $50 \mathrm{MPa}$ and $68 \mathrm{MPa}$ respectively: (e ) top and (f) bottom portion of service exposed reformer tube.

part of the specimen supports the applied load and finally ruptured with shear mode or with sliding. Actually, the facet looks smeared by sliding. Although, samples were crept under identical stress-temperature condition, it is observed that mode of failure is different. Similar kind of observation was found by Garofalo et al. [7] and Roy et al. [28].

For crept service exposed material, fracture was mainly due to the creep rupture mechanism in tertiary region which varied from ductile to quasi cleavage failure. Possibly, as a result of this variation in the mode of fracture, there is a substantial amount of scatter, both in the creep response and creep rupture time. Oxide scale formation (Figure 5e,i,g,k) decreases the effective cross section area for the load bearing capacity of the specimen. Variation in the mode of fracture may be due to oxide scale formation on the crept specimen which led to catastrophic failure. In addition, though oxide scale reduces the effective cross sectional area of the specimen, the combined effect of inhomogeneity in microstructure of service exposed material is equally important. Hence, one may say that oxidation effect in combination with the influence of change in microstructure could be responsible for variation in the mode of fracture and creep response.

\section{Quantification of creep cavities after rupture}

Population of voids (appearing grey) at various stresses and strains is shown in Figure 1. The population of void cavity on the creep ruptured 

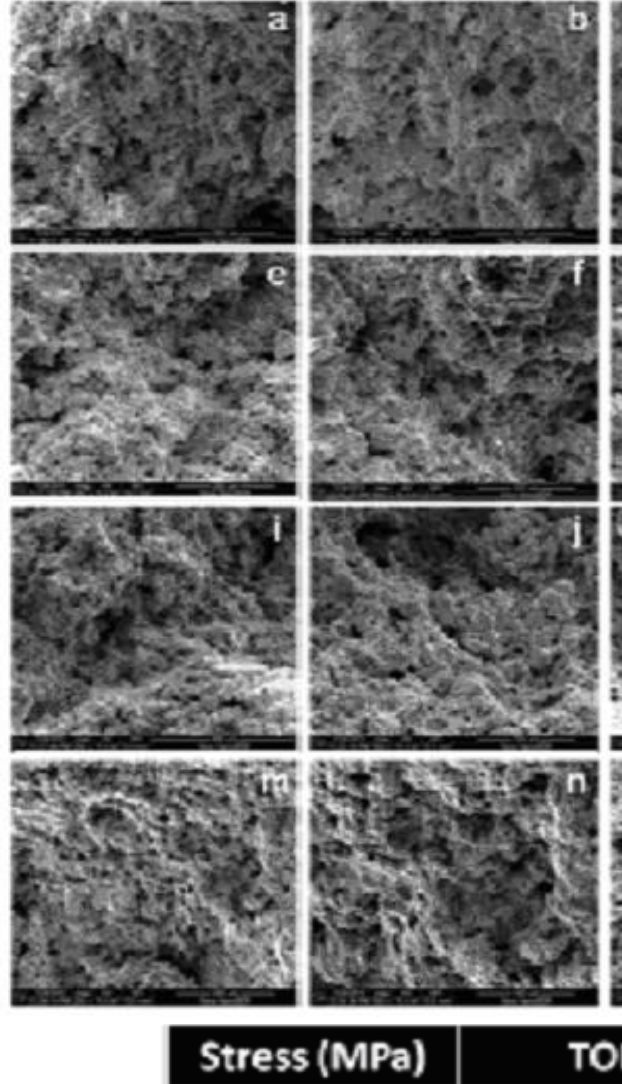
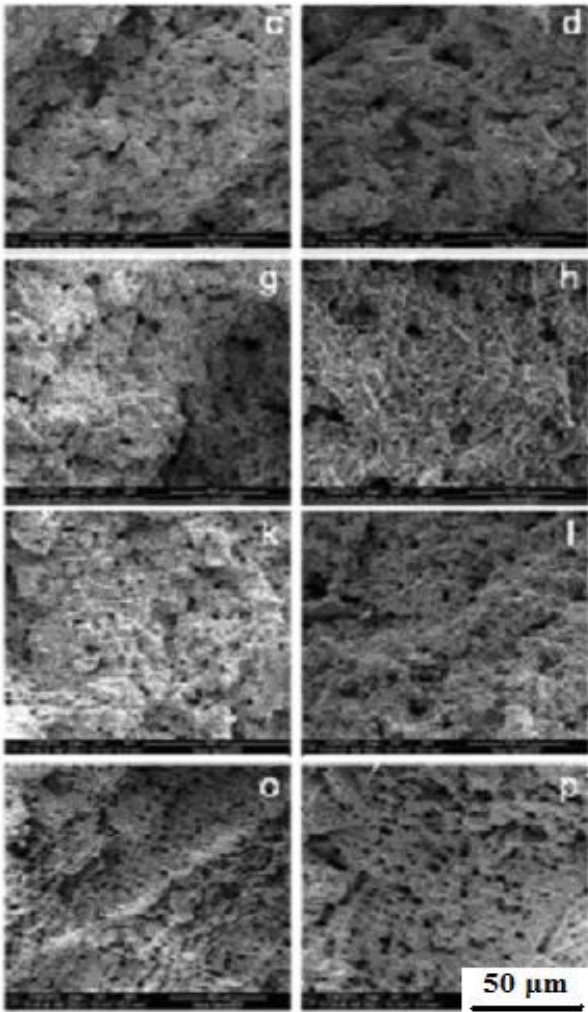

BOTTOM

a, b

c, d

g, $h$

$k$, I

$0, \mathrm{p}$

Figure 5: Fractograph of crept service exposed specimens (both top and bottom portion of the tube) tested at $870^{\circ} \mathrm{C}$ in the stress range of $52-68$ MPa.

surface was found to be nucleated either at Grain Boundary (GB), or at Grain Boundary Triple Point (GBTP) predominantly and also in the vicinity of other carbide particles. A similar kind of metallographic technique was employed to measure the extent of marten site at various strain reported elsewhere [17], which is already well established.

There is a systematic correlation of void/creep cavitations and the applied stress at GB (grain boundary) and GBTP (grain boundary triple point). It was found that the probability of GBTP cavitations [14] was almost three times than that of GB voids (Figure 6) where the initial inclusion volume fraction all the specimens remained unaltered. Void distribution at GB and GBTP was inhomogeneous in the deformed austenite dendrites. The damage evolution law for $\mathrm{A}^{\star}$ can be obtained by relating $\mathrm{A}^{\star}$ to $\mathrm{A}$. The $\mathrm{A}$ - parameter which is equated to the damage parameter $\omega$, from $\mathrm{K}$-model has been related to the measured parameter $\mathrm{A}_{1}$ as following [29]:

$$
\mathrm{A}=\omega=\mathrm{A}_{1} \times 4 / \Pi
$$

Where $A_{1}$ is number fraction of cavitated grain boundaries on the reference line.
Appearance of voids at GB and GBTP along a reference line is revealed in Figure 6a). Since quantification of voids in the present crept material has shown (Figure $6 \mathrm{~b}, 6 \mathrm{c}$ ) that the probability of number of creep cavities or voids at the $\operatorname{GBTP}\left(\mathrm{A}_{2}\right)$ junctions along a reference line, is three times than that of the number of creep cavities or voids occurring along the $G B\left(A_{1}\right)[14]$, a relation $A_{1}$ and $A_{2}$ can be obtained as:

$$
\mathrm{A}_{2}=3 \mathrm{~A}_{1}=3 \mathrm{~A}^{\star} \Pi / 4
$$

Cavitated GB and GBTP counted for the determination of $\mathrm{A}_{1}$ and $\mathrm{A}_{2}$ parameters were measured according to Riedel [30]. GB and GBTP were considered to be damaged when it contained cavity of size greater than or equal to $1 \mu \mathrm{m}$. Using the stereological results from Eggler et al. [29], $A^{*}$ is derived as the cumulative contribution from damaged grain boundaries $\left(A_{1}\right)$ and number of creep cavities or voids at the grain boundary triple points $\left(A_{2}\right)$. Therefore, we arrive at the following:

$$
\mathrm{A}^{*}=\mathrm{A}_{1}+\mathrm{A}_{2}=\Pi \mathrm{A} / 4+3 \Pi \mathrm{A} / 4=\Pi \mathrm{A}
$$

It is more appropriate if $3 \mathrm{D}$ measurements of creep cavitation could be carried out. However, due to experimental limitation 2D measurement was resorted to, extensively. 
Citation: Ray AK, Roy N, Raj A, Matwa M, Davuluri A, et al. (2014) Uncertainty in Damage Assessment and Remaining Life Prediction of Engineering Materials Used In Petrochemical Industry. J Pet Environ Biotechnol 5: 181. doi:10.4172/2157-7463.1000181

a

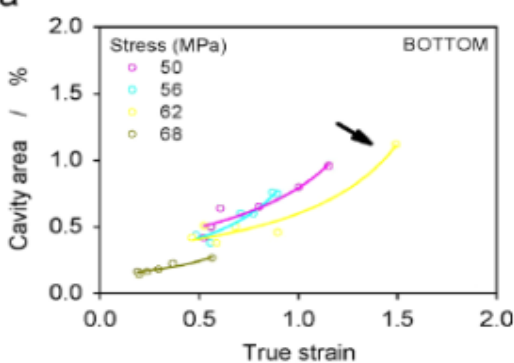

C

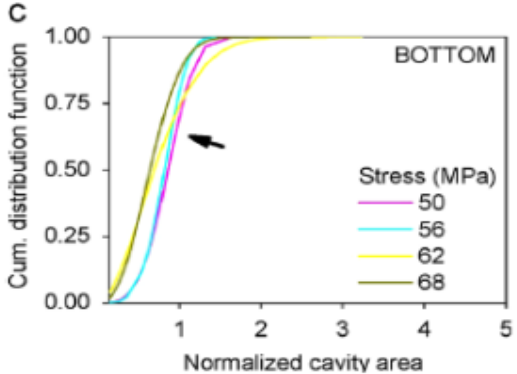

b

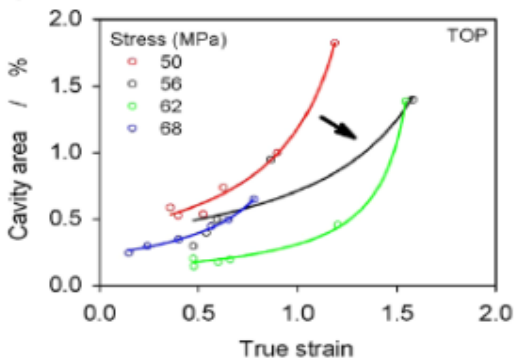

d

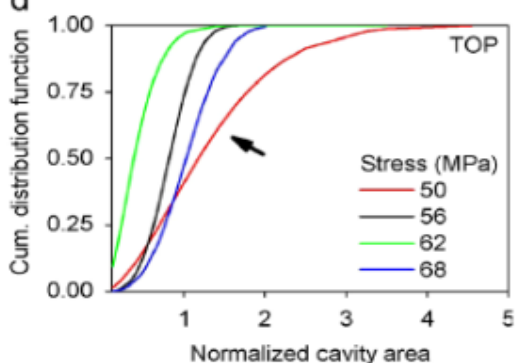

Figure 6: Cavity area as a function of strain at different stress levels: (a) bottom and (b) top tubes. Cumulative distribution functions as a function of normalized cavity area (cavity area/true strain) for (c) bottom and (d) top tubes [14].

a

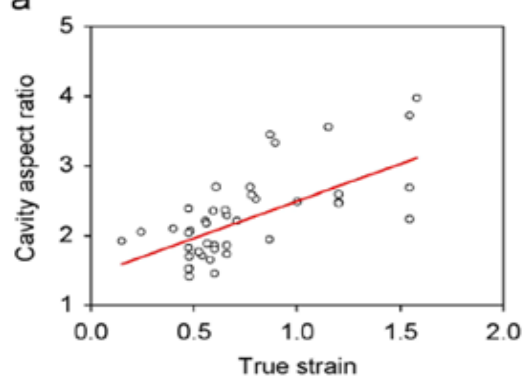

b

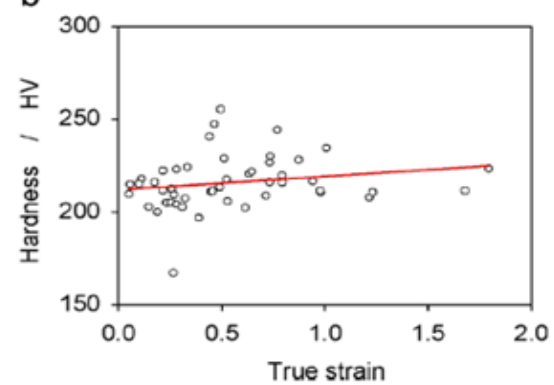

Figure 7: Cavity aspect ratio and (b) hardness as a function of strain for all the stress levels for both top and bottom tubes together [14].

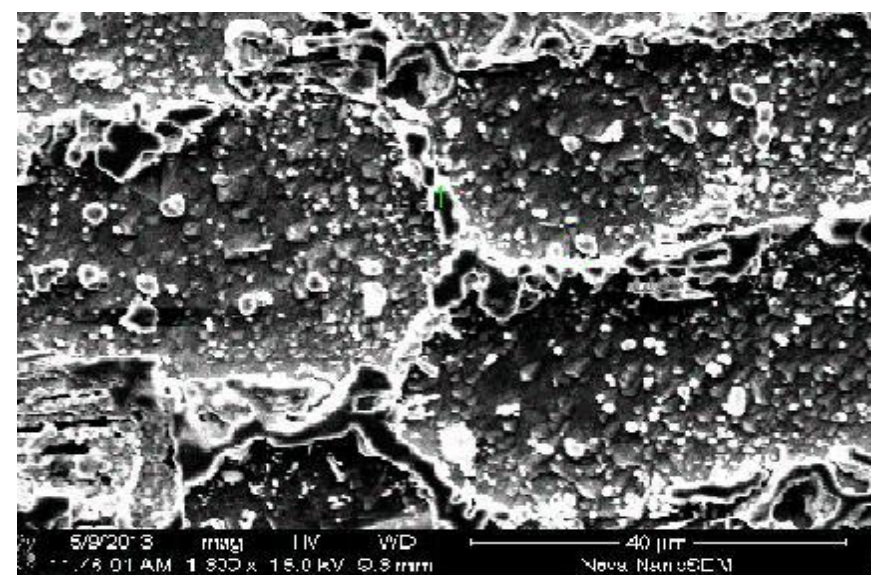

(a)

Figure 8a: (a) SEM micrograph at $50 \mathrm{MPa} / 870^{\circ} \mathrm{C}$, revealing creep cavitation/void formation at GB (white arrow) and at GBTP (black arrow) which were digitally recorded along a reference line indicated in white. 


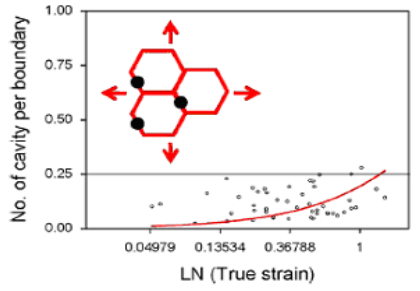

(b)

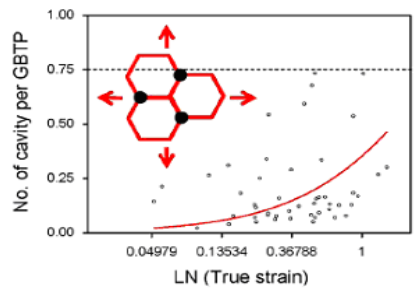

(c)

Figure 8b: (b) Number of creep cavity formation at GB and at (c) GBTP as a function of strain for all stress levels for both the top and bottom tubes together [14]. The lines in the graphs indicated the upper boundary limit of the voids/cavity. The best fit curve for number of creep cavity is represented in Figure 8 ( $b$ \& c).

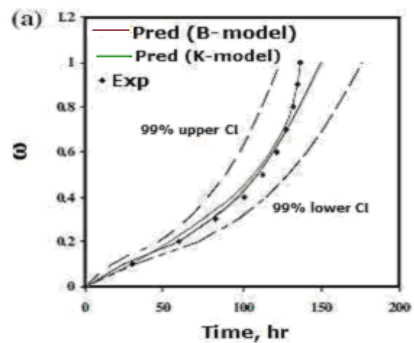

(c)
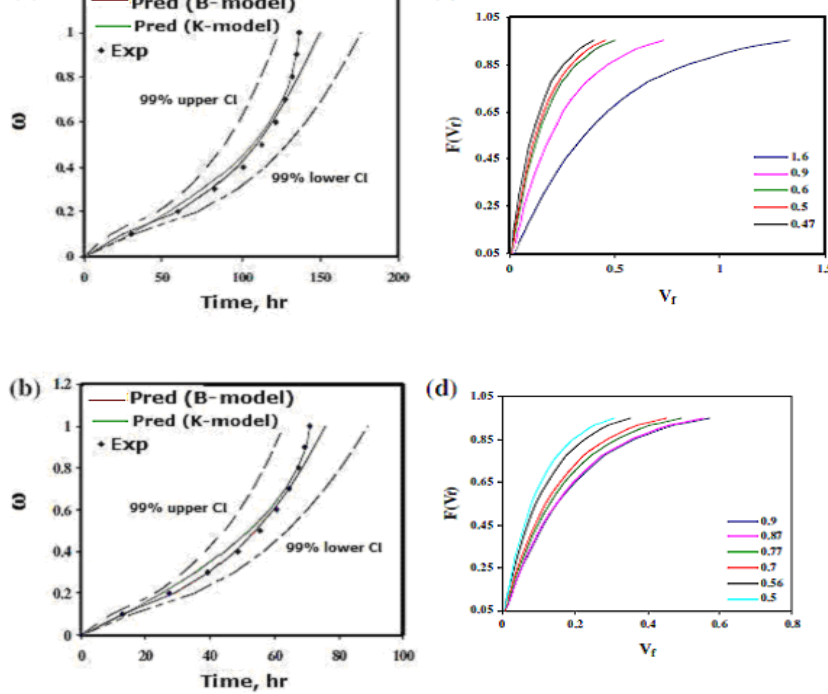

Figure 9a: Comparison of the experimental and predicted values of mean time to reach a specified damage state by both Bogdanoff model and CDM approach with relative Confidence Interval $(\mathrm{Cl})$ at $870^{\circ} \mathrm{C} / 56 \mathrm{MPa}$ : (a) top and (b) bottom portion of service exposed reformer tube. Probability distribution of void area fraction at $870^{\circ} \mathrm{C} / 56 \mathrm{MPa}$ (c) top and (d) bottom portion of service exposed reformer tube.

\section{Damage modelling for service exposed reformer tubes}

In this section, the proposed model based on Bogdanoff model [10] is compared with Kachanav [13] CDM model from both phenomenological and statistical points of view. The phenomenological comparison helps to investigate whether the proposed model could predict the time to reach a specified damage state. Figure 9ia,9ib) shows the comparison of the proposed model with the Kachnov's damage model. The proposed model fits the Kachanov's damage model very well, and it can describe the sudden changes of the creep damage in the tertiary part as well.

The Bogdanoff model [10] has been used to predict creep damage evolution as a function of time. Since the probability of reaching a specific state of damage at any instant of time is known, a Monte-Carlo simulation has been carried out to estimate the time to reach a specific damage state. Also, the Kachanov [13] and Rabotnov [18] model has been used to predict creep damage evolution. A comparison of the experimental and predicted values of mean time to reach a specified damage state by both Bogdanoff model and CDM approach with relative Confidence Interval (CI) is shown in Figure 9ia,9ib for both top and bottom portion of the reformer tube The two extreme lines contain the range in which $99 \%$ of all mean times to reach a specified damage state will lie with $99 \%$ certainty. It is of prime importance to mention that the damage prediction by both the model is in close agreement with experimental data.

The probability of failure due to creep cavity area at various strains is calculated using Equation (18). It is well approximated with the aid of Weibull distribution as shown in Figure 9ic,9id) for various true strain conditions. As expected, it is observed that the distributions shift towards the higher range of creep cavity with increase in strain.

The Kachanav's damage model is deterministic in nature, while prediction of failure is inherently a probabilistic problem due to associated scatter. Matic and Sruc [31] emphasized the need for probabilistic approach to describe the physics-based models and their corresponding parameters. The proposed probabilistic model could explain the creep characteristics and damage evolution of service exposed HP-40 grade of steel used in hydrogen reformer. It would be highly beneficial if estimation of remaining life of component could effectively be positioned within the scatter band of creep strain vs time plots. Nucleation of cavities being deterministic, the scatter band in damage evaluation under identical test conditions could be easily 

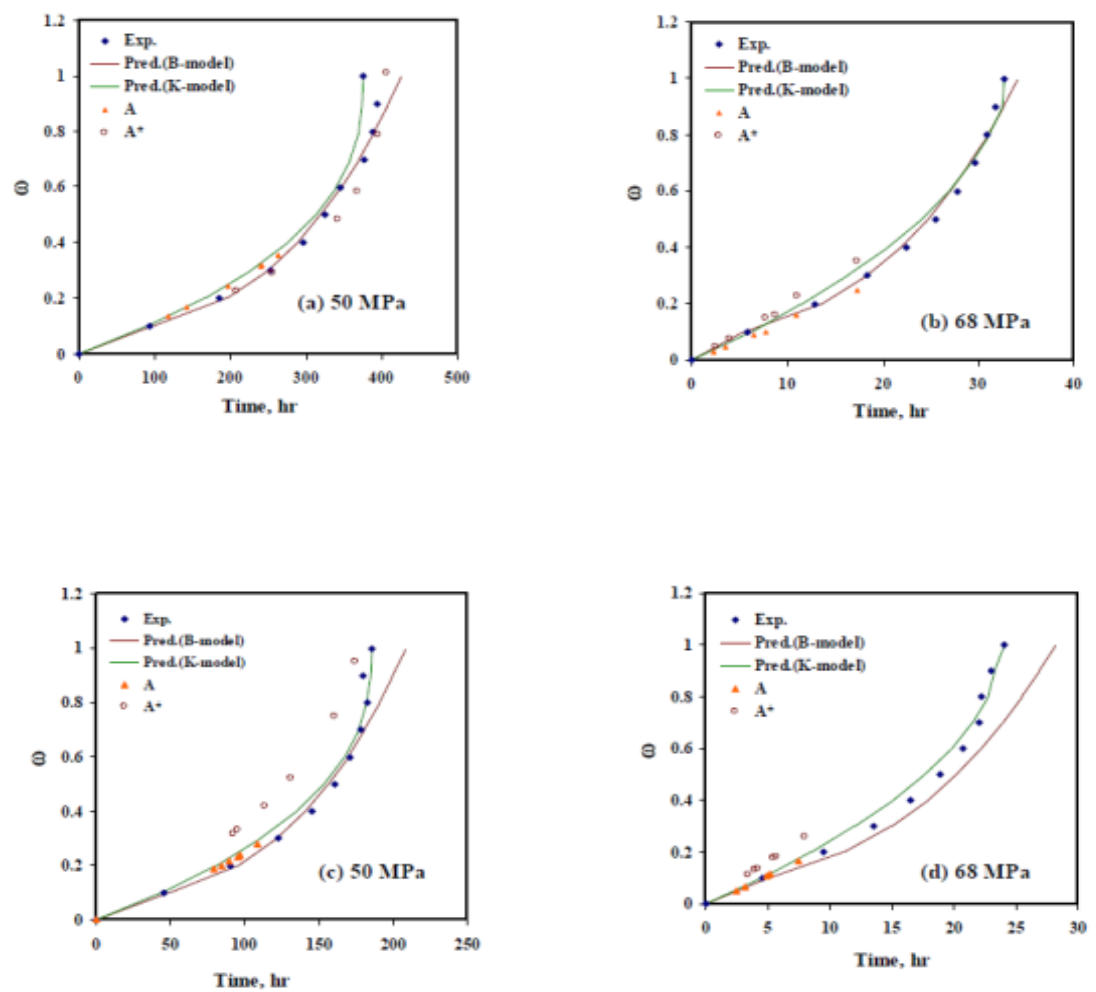

Figure 9b: Comparison of damage parameter $A$ and $A^{*}$ with the damage prediction from probabilistic model as well as $\mathrm{K}-\mathrm{model}$ at $870^{\circ} \mathrm{C}$ : $(\mathrm{a}, \mathrm{b})$ top and $(\mathrm{c}, \mathrm{d})$ bottom portion of service exposed reformer tube.

estimated by carrying out a Monte Carlo Simulation. This explains as to why such a large interval in scatter band was possible from both the models. It actually depicts estimation of all average times required to reach a specific damage state from both the models i.e. K- model as well as B- model [32,33].

The microstructurally quantified damage (creep cavitation /voids) is in close agreement with the damage prediction curves based on $\mathrm{K}$-model as well as $\mathrm{B}$-model, at low stress $(50 \mathrm{MPa})$ whereas at high stress $(68 \mathrm{MPa})$ it could correlate well till the mid region of the predicted curves, above which cavity measurement was practically not feasible (Figure 9ii). This is because at high temperature and at high stresses grain boundary sliding occurs discontinuously with time and amount of shear displacement is not uniform in the adjacent grains. But grain boundary at high temperature and high stresses can be accommodated by formation of folds at the grain boundaries [34]. When distribution of shear stress is non-uniform amongst the adjacent grains, at high stresses these folds may not be apparent as clear voids and possibly due to this fact void quantification under light optical microscope and SEM was only possible till the mid portion of the predicted curves (Figure 9ii). It is observed that the $A^{*}$ is more sensitive to life prediction than A because it picks up the localized damage in the form of voids which actually forms in the tertiary region of creep life.

\section{Residual life prediction of service exposed reformer tubes}

There was no evidence of creep cavitation and voids in the service exposed tubes in as received condition, therefore only as far as creep strength and residual life at $870^{\circ} \mathrm{C} / 13.46 \mathrm{MPa}$ is concerned, there is no appreciable degradation due to service exposure and it is justified that it possible to obtain an additional minimum balance life of $>10$ years for both the top as well as bottom portions of the reformer tubes in the present investigation. However, at the design temperature of $920^{\circ} \mathrm{C}$ /13.46 MPa an additional minimum balance life of 7 years and 6 years for the top and bottom portions of the 11 years' service exposed primary reformer tubes respectively is possible from Stress rupture plots (Figure 10 and Table1), provided there is no evidence of any localised damage in the form of surface cracks, cavitation or dents and overheating of the tubes resulting in early onset of creep damage. Another check for safety of the service exposed tubes, similar to the current work, in terms of residual life is recommended to be carried out after expiry of about 2.5 years of service life from the view of economical and safety reasons. Also during shut down of the plant, NDT (non-destructive) tests viz. Dimensional (thickness and diameter) measurement, hardness measurement and in situ metallography may be carried out to assess the condition of the materials for their future serviceability.

\section{Life assessment of 55 years' service exposed CCU reactor and FPU distillation column materials from accelerated creep/ stress rupture tests, creep damage assessment and LMP equation}

Optical microscopy was carried out on as received as well as creep fractured specimens of 55 years' service exposed reactor and column material. Details of the procedure are reported and discussed elsewhere [15]. For as received material, samples were observed thickness wise, whereas, for crept specimens, samples were cut parallel to stress axis starting from fracture tip and mechanically polished with various grades of emery paper. The microstructures are shown in Figure 11,12. Detailed microstructural studies of as received material and fractured crept specimens as reported in [15] have revealed following features: 
Citation: Ray AK, Roy N, Raj A, Matwa M, Davuluri A, et al. (2014) Uncertainty in Damage Assessment and Remaining Life Prediction of Engineering Materials Used In Petrochemical Industry. J Pet Environ Biotechnol 5: 181. doi:10.4172/2157-7463.1000181

Page 12 of 16

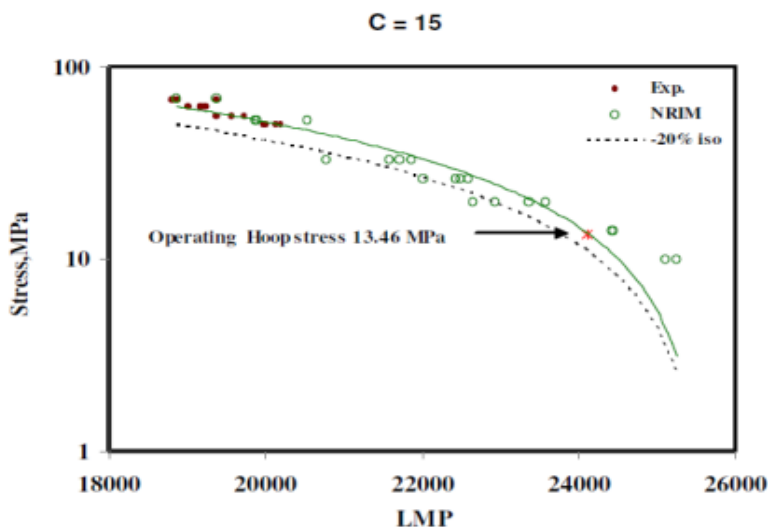

(a)

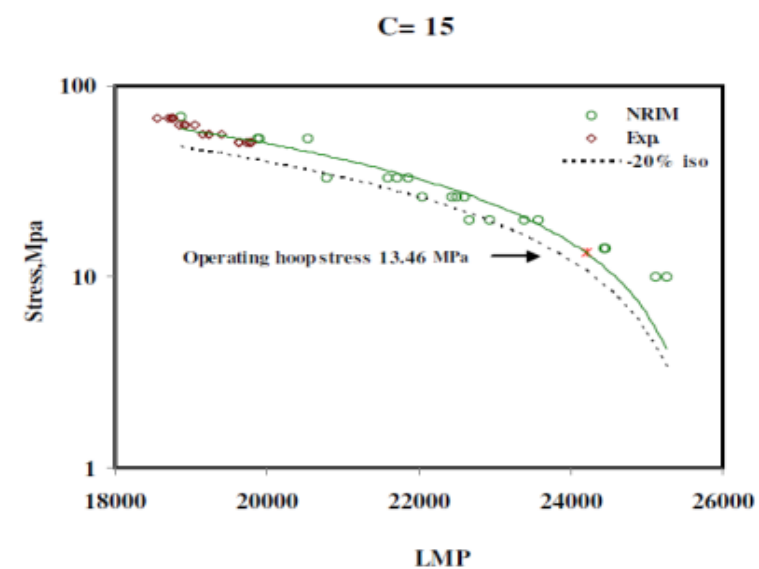

(b)

Figure 10: Stress vs LMP Plot for 11 years service exposed Reformer tube materials (a) top and (b) bottom for comparison with $-20 \%$ NRIM standard data line. All data fall on the NRIM virgin data line [25].

(i) It was noteworthy that creep cavities varied between $0.25-0.5 \%$ and $0.096-0.21 \%$ in crept specimens of service exposed CCU reactor base and weld material respectively. However, no creep cavity was observed in as-received CCU reactor base and weld material. Variation in percentage graphitization was between $6-9 \%$ and almost nil in crept specimens of service exposed CCU reactor base and weld material respectively. Also, 6\% and almost nil graphite were observed in asreceived CCU reactor base and weld material respectively. There was marginal increase both in creep cavitation and percentage graphitization for service exposed crept CCU reactor specimens compared to asreceived service exposed CCU reactor specimens.

(ii) No creep cavity was observed both in as-received and crept specimens of service exposed FPU column base material. But, asreceived FPU weld material had only around $0.06 \%$ voids. However, crept FPU weld material had $0.095-0.25 \%$ creep voids.

(iii) Variation in percentage graphitization was between $9-16 \%$ and 3-5\% in crept specimens [15] of service exposed FPU column base and weld material respectively. However, $\sim 8 \%$ and $\sim 3 \%$ graphite were observed in as-received FPU column base and weld material respectively. A similar trend in marginal increase both in creep cavitation and percentage graphitization as of crept CCU reactor specimens was observed for service exposed crept FPU column specimens too, compared to as-received service exposed CCU reactor and FPU column specimens respectively. Quantification of creep cavitation as well as graphitization was made with the help of Olympus Image Analyzer (Model: GX51) [15].

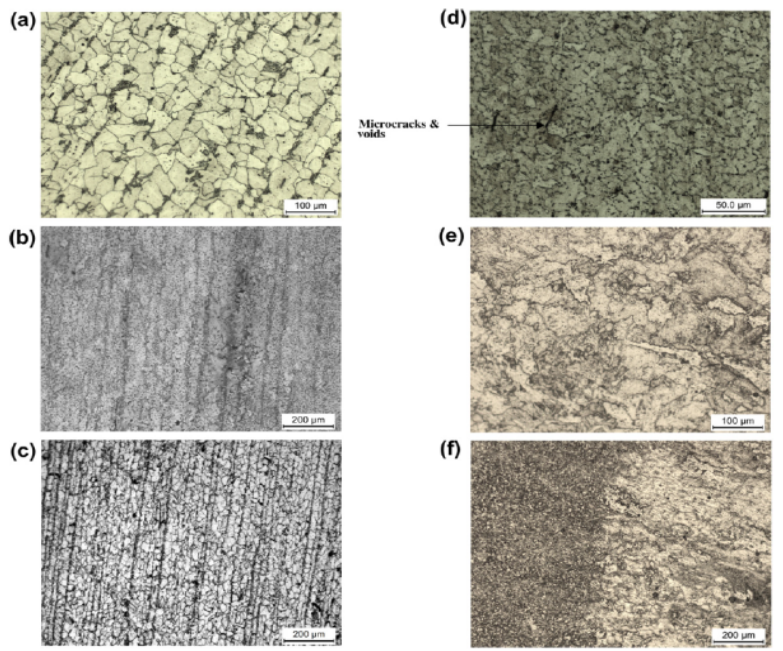

Figure 11: Optical micrograph of service exposed CCU reactor (a) base material in as received condition showing ferritic pearlitic structure. (b) base material in crept condition at $78 \mathrm{MPa} / 515^{\circ} \mathrm{C}$ showing very fine grain structure. (c) base material crept at $98 \mathrm{MPa} / 515^{\circ} \mathrm{C}$ showing graphite nodule associated with micro-cracks. (d) weld material in as received condition showing microcracks and voids. (e) weld materials crept at $78 \mathrm{MPa} / 515^{\circ} \mathrm{C}$ showing coarse grains and graphite nodules in the base region and (f) showing transition zone of fine grains in weld region and coarse ferrite (white) grains in base metal regions [15].
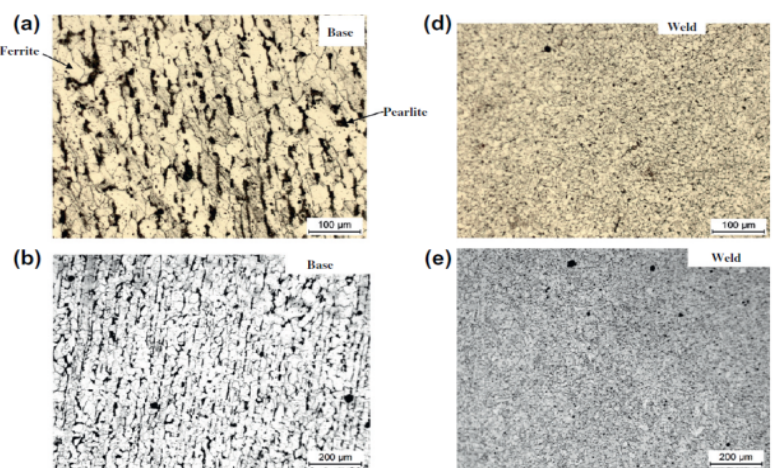

(e)
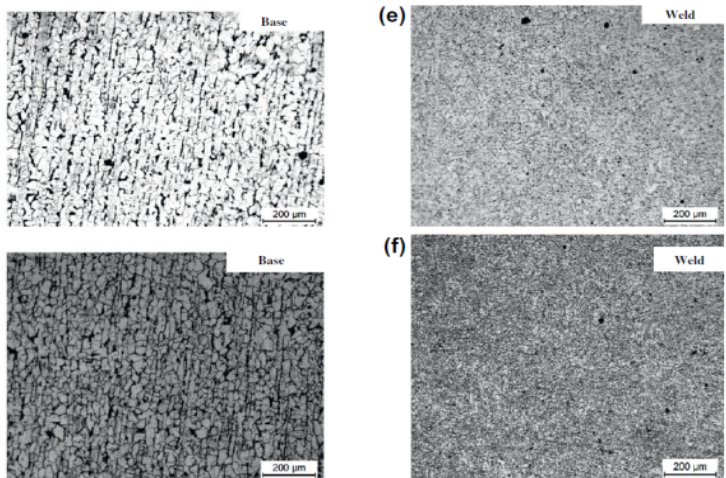

Figure 12: Optical micrograph of service exposed FPU column (a) base material in as received condition showing ferritic pearlitic structure. (b) base material in crept condition at $78 \mathrm{MPa} / 515^{\circ} \mathrm{C}$ showing elongated grains of coarse ferrite (white) and dispersed pearlite (dark). (c) base material crept at 98 $\mathrm{MPa} / 515^{\circ} \mathrm{C}$ showing ferritic pearlitic structure. (d) weld material in as received condition showing ferritic pearlitic structure. (e) weld material crept at $78 \mathrm{MPa} /$ $515^{\circ} \mathrm{C}$ showing fine grains of ferrite(white) and pearlite (dark) and ( $f$ ) weld material crept at $98 \mathrm{MPa} / 515^{\circ} \mathrm{C}$ showing showing fine grains of ferrite(white) and pearlite (dark)[15] 
(a)

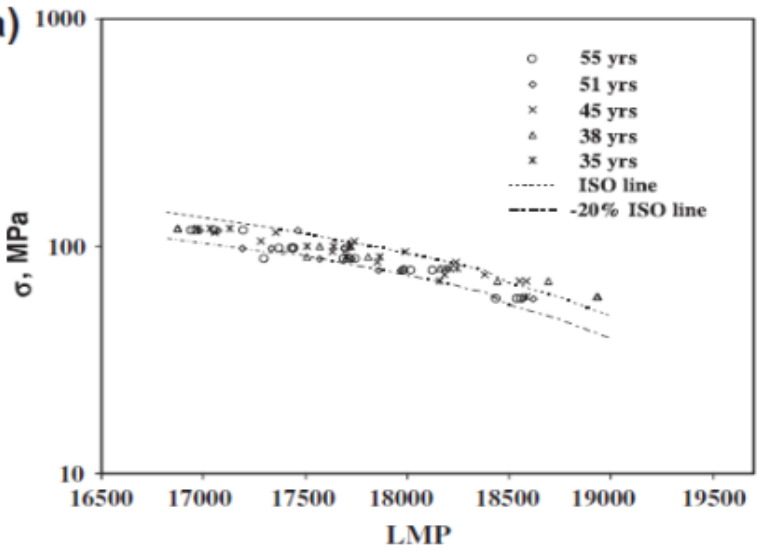

(b)

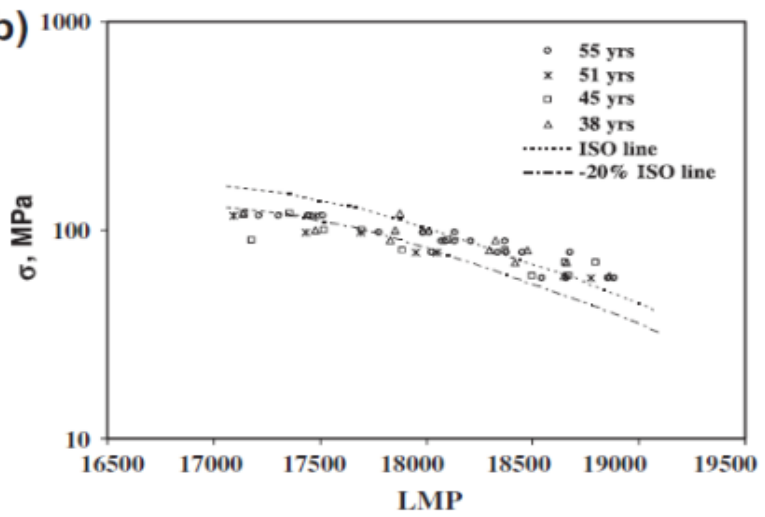

Figure 13: Stress rupture plot for service exposed (a) $\mathrm{CCH}$ reactor and (b) FPU column material [15].

Results of accelerated stress rupture tests conducted on reactor and column materials are revealed in Figure 13. The remaining creep life prediction of reactor as well as column materials was made using applied stress versus LMP curves. The plots contain the lower bound ISO curve for the respective grade of material for comparison. Because of uncertainty factors in materials and experimental conditions, creep rupture data generally exhibits dispersity, as shown in Figure 13a,13b, where the experimental data distributes scattering around the master curve in stress time-temperature plot. Uncertainty involved in calculating LMP (Larson Miller Parameter) value has been given prime importance because it is a function of rupture time. The placing of confidence bounds around any failure time prediction requires knowledge of the failure time distribution. In the case of the reactor, all weldment showed significant elongation indicating soundness of the weld [15]. However, for the column material, (Table 2), the weld metal showed poor creep ductility (the lowest being $4 \%$ ). A comparison of rupture data generated [15] with those obtained 4 years before, indicated that the rupture time of weld metal at any given stress had decreased 69\% compared to the previous study (Table 2). At lower stress levels, both reactor and column materials showed a convergence with the standard ISO (master curve) curve. ISO curve, lower bound data is generally taken as the reference line for safe life prediction. Such an exercise had been performed in earlier investigations $[33,34]$ as well for the same grade of materials. All base metal data fall on the lower bound ISO curve ( $-20 \%$ data curve) and weld metal data have marginally fallen below the ISO curve. This is usually anticipated that with increase in service exposure, more creep damage is expected to accumulate in the material resulting in a decreased rupture time. However, the drastic reduction in creep ductility of the column weld is a matter of concern from the structural integrity point of view.

A comparison of experimental and predicted creep damage $\omega$, using Equation (5) i.e.,

\begin{tabular}{|c|c|c|c|c|c|c|c|}
\hline Material & Specimen & \multicolumn{2}{|c|}{ Temperature ${ }^{\circ} \mathrm{C}$} & $\begin{array}{c}\text { Stress } \\
\left(\mathbf{K g} / \mathbf{m m}^{2}\right)\end{array}$ & $\begin{array}{l}\text { Rupture } \\
\text { time (h) }\end{array}$ & EL(\%) & $\begin{array}{l}\text { RA } \\
\text { (\%) }\end{array}$ \\
\hline \multirow{13}{*}{ Ccu reactor } & Base & & 515 & 12 & 44 & 28 & 53 \\
\hline & Base & & 515 & 12 & 32 & 40 & 49 \\
\hline & Base & & 515 & 10 & 111 & 31 & 47 \\
\hline & Base & & 515 & 10 & 138 & 36 & 41 \\
\hline & Base & & 515 & 9 & 307 & 29 & 36 \\
\hline & Base & & 515 & 9 & 282 & 29 & 44 \\
\hline & Base & & 515 & 8 & 738 & 23 & 35 \\
\hline & Base & & 515 & 8 & 1001 & 25 & 49 \\
\hline & Base & & 515 & 6 & 3529 & 15 & 33 \\
\hline & Base & & 515 & 6 & 2495 & 9 & 25 \\
\hline & Weld & & 515 & 12 & 66 & 7 & 16 \\
\hline & Weld & & 515 & 10 & 291 & 8 & 20 \\
\hline & Weld & & 515 & 9 & 90 & 5 & 20 \\
\hline \multirow{14}{*}{$\begin{array}{l}\text { FPU-D1 } \\
\text { column }\end{array}$} & Base & & 515 & 12 & 51 & 20 & 42 \\
\hline & Base & & 515 & 12 & 66 & 24 & 46 \\
\hline & Base & & 515 & 10 & 483 & 9 & 29 \\
\hline & Base & & 515 & 10 & 262 & 15 & 55 \\
\hline & Base & & 515 & 9 & 740 & 12 & 25 \\
\hline & Base & & 515 & 9 & 918 & 9.3 & 24 \\
\hline & Base & & 515 & 8 & 1327 & 5 & 20 \\
\hline & Base & & 515 & 8 & 3572 & 11 & 25 \\
\hline & Base & & 515 & 6 & 5971 & 8 & 34 \\
\hline & Base & & 515 & 6 & 2415 & 8 & 39 \\
\hline & Weld & & 515 & 12 & 99 & 10 & 31 \\
\hline & Weld & & 515 & 10 & 741 & 2.5 & 18 \\
\hline & Weld & & 515 & 9 & 1480 & 4 & 13 \\
\hline & Weld & & 515 & 8 & 537 & 2.1 & 12 \\
\hline Material & Specir & nen & Temp, $\left({ }^{\circ} \mathrm{C}\right)$ & $\begin{array}{l}\text { Stress, } \\
\left(\mathrm{Kg} / \mathbf{m m}^{2}\right)\end{array}$ & $\begin{array}{l}\text { Rupture } \\
\text { Time, (h) }\end{array}$ & $\begin{array}{c}\% E L \\
(\%)\end{array}$ & $\begin{array}{l}\text { RA } \\
(\%)\end{array}$ \\
\hline \multirow{12}{*}{ CCU reactor } & Wel & & 515 & 12 & 105 & 10 & 16 \\
\hline & Wel & & 515 & 10 & 204 & 6.3 & 22 \\
\hline & Cross & weld & 515 & 12 & 26 & 26 & 67 \\
\hline & Cross & weld & 515 & 10 & 48 & 18 & 43 \\
\hline & Cross & weld & 515 & 9 & 228 & 19 & 54 \\
\hline & Cross & weld & 515 & 8 & 333 & 16 & 46 \\
\hline & Cross & weld & 515 & 6 & 2608 & 9 & 28 \\
\hline & Bas & & 515 & 6 & 3000 & 27 & 14 \\
\hline & Bas & & 515 & 8 & 456 & 28 & 42 \\
\hline & Bas & & 515 & 9 & 144 & 30 & 48 \\
\hline & Bas & & 515 & 10 & 72 & 31 & 47 \\
\hline & Bas & & 515 & 12 & 34 & 29 & 48 \\
\hline \multirow{8}{*}{ FPU-D1 Column } & Bas & & 515 & 12 & 36 & 43 & 78 \\
\hline & Bas & & 515 & 10 & 96 & 33 & 76 \\
\hline & Bas & & 515 & 8 & 576 & 38 & 72 \\
\hline & Bas & & 515 & 6 & 4704 & 33 & 49 \\
\hline & Wel & & 515 & 12 & 110 & 22 & 70 \\
\hline & Wel & & 515 & 10 & 204 & 25 & 61 \\
\hline & Wel & & 515 & 8 & 432 & 31 & 38 \\
\hline & Wel & & 515 & 6 & 4104 & 14 & 49 \\
\hline
\end{tabular}

Table 2: (a) Stress rupture properties of (a) 55 year and (b) 51 year service exposed CCU reactor and FPU column materials. 

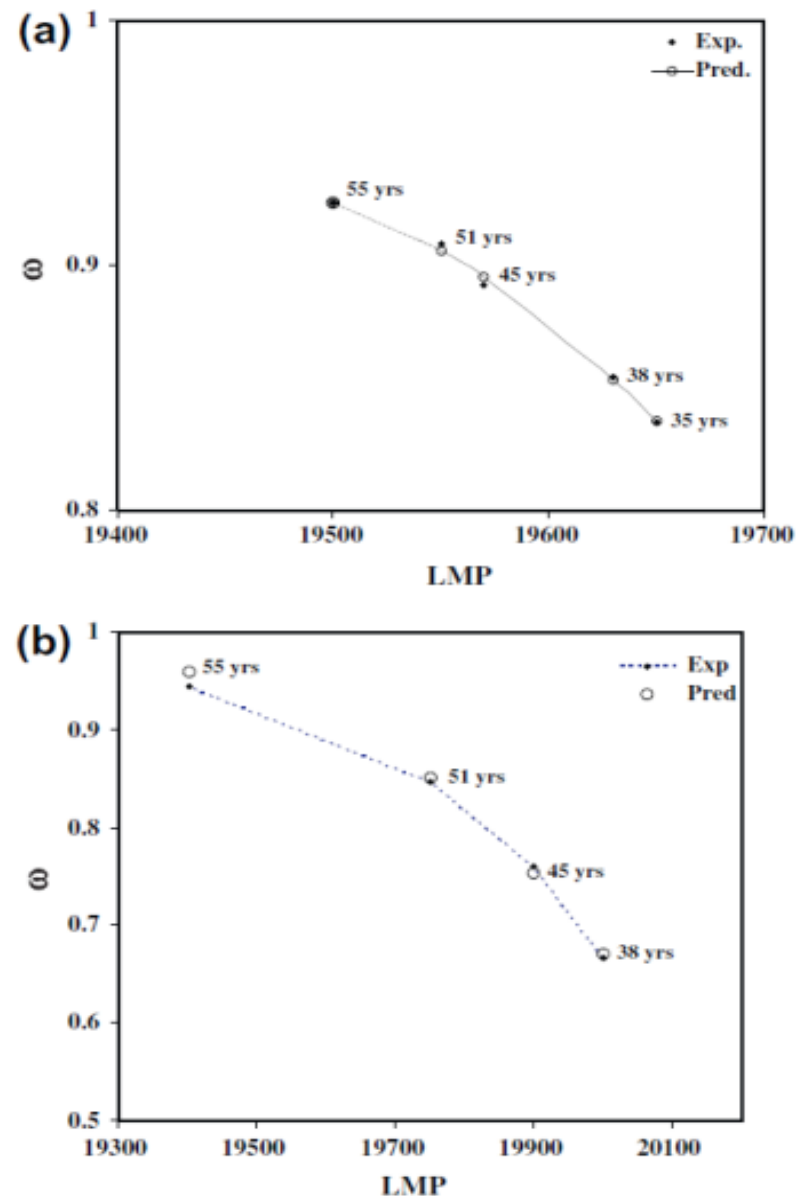

Figure 14: Comparison of experimental and predicted creep damage from Eqn (5) of various shut down for (a) CCU reactor and (b) FPU column material.

$$
\omega=a_{0}+a_{1} \mathrm{LMP}+a_{2} \mathrm{LMP}^{2}
$$

,for various shut downs of (a) CCU reactor and (b) FPU column material has been made and is revealed in Figure 14. It depicts that with increase in service exposure time in years, $\omega$ was found to be on the higher side which is expected.

Uncertainty is involved in calculating LMP value because it is a function of rupture time. Figure 15 shows the effect of variation in LMP on Remaining Life (RL) calculation for reactor and column materials respectively, from the method reported in [15]. It has been well documented and reported in literature $[7,23]$ that stress rupture tests always reveals scatter in rupture data. To incorporate data scatter band in stress rupture tests, Monte Carlo simulation has been carried out where LMP value is varied between ISO mean line and ISO $(-20 \%)$. Corresponding to each LMP value, remaining life and normalized creep damage was calculated using Equations. (2)-(4). Variability of normalized creep damage using Equation (6) for reactor and column materials is well approximated with the aid of Weibull distribution as shown in Figure 15a,15b. It is observed that the distributions shift towards the higher range of damage with increase in service exposure time (Figure 16a,16b). Similarly, the probability of distribution of creep damage reveals that the distributions also shift towards the higher range of damage with increase in service exposure time for CCU reactor as well as FPU column material (Figure 17).
Remaining life of reactor and column materials after 55 years of service exposure with relative Confidence Interval (CI) are reported in Table 3. Monte-Carlo simulation could predict remaining life for exposed CCU reactor and FPU column materials with $99 \%$ confidence level. The lower and upper confidence interval indicates that $99 \%$ cases the remaining life will lie in this range with $99 \%$ certainty [15]. The reactor material needs replacement (Table 3 ) after a maximum service period of one year, as they are not in healthy state of health, in order to avoid plant accident resulting in huge loss of life and material property. The distillation column material can remain in service for at most three years and they should also be replaced for economic and safety reasons.

Future research would primarily be aimed at emphasizing on how best the design criteria could be met by real service conditions, possible ways to increase remnant life of similar components, improvements to the testing devices etc.

\section{Conclusions}

i. Scatter observed in creep deformation and creep strain rate curve at $870^{\circ} \mathrm{C}$ of the top as well as bottom portion of the service exposed reformer tube at various stress conditions was probably due to variation in mode of fracture and scatter in voids.

ii. From statistical point of view, the pattern of Weibull distribution followed for analyzing probability of rupture due to cavity or void area in the case of reformer tubes shifts with increase in
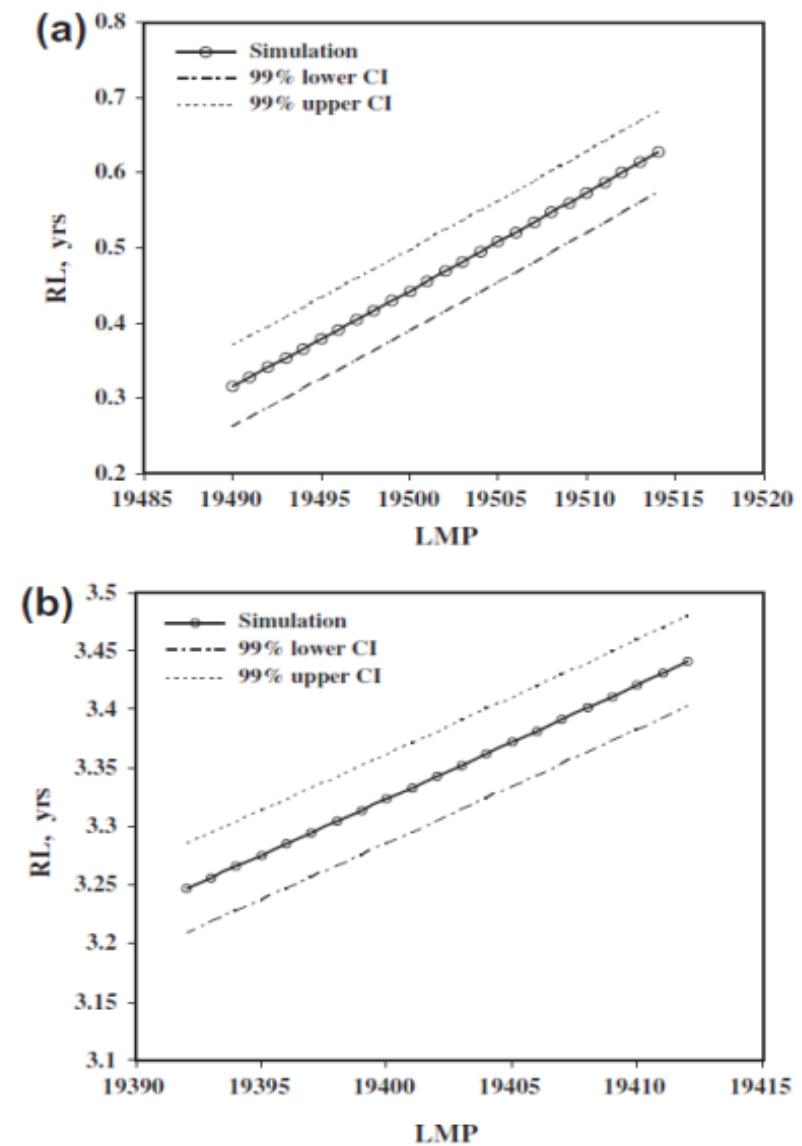

Figure 15: Variation of LMP with remaining life calculation for (a) CCU reactor and (b) FPU column material. 

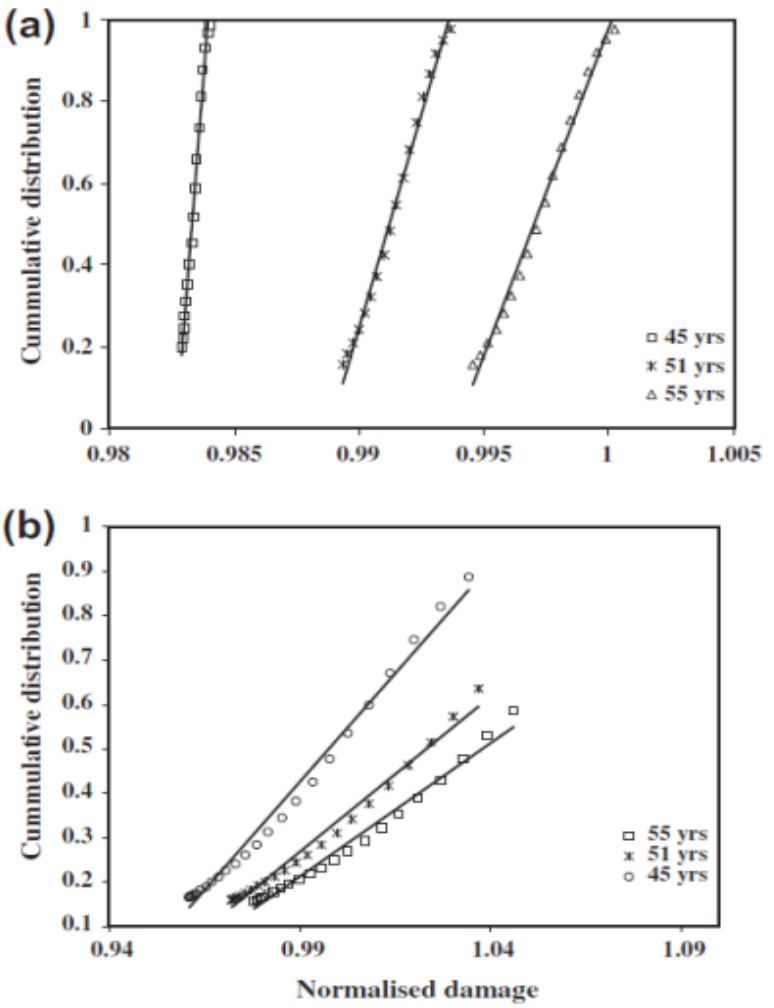

Figure 16: Normalized creep damage using Eqn (6) follows Weibull distribution: (a) CCU reactor and (b) FPU column material [15].The best fit line for the points is represented in the graph.

true strain towards the higher population of void. For CCU reactor and FPU column materials, normalized creep damage could also be well-approximated with Weibull distribution which shifts towards the higher range of damage with increase in service exposure time.

iii. Experimental data for estimating damage in the material, agrees well with simulation based CDM (Continuum Damage Mechanics) model as well as B-model for prediction of damage with scatter associated with it. In other words, estimation of average time to reach a specific damage state from both the models is in close agreement with that of experimental data. This pertains to the sudden changes in creep damage in the tertiary region as well.

iv. Unlike at low stress, the microstrucrally determined damage parameters $\mathrm{A}$ and $\mathrm{A}^{*}$ when compared with the damage prediction by the probabilistic model for the reformer tubes, clearly indicate that the prediction could only correlate till the mid region of the curves at high stress where cavity measurement was practically feasible. $A^{*}$ is more sensitive to life prediction than A because it picks up the localized damage in the form of voids which actually forms in the tertiary region of creep life.

v. A residual life of $>10$ years is estimated at the operating stresstemperature conditions of the top as well as bottom portion of the service exposed primary reformer tube. This is realistic, only if there is absence of any form of localised damage in the material. Monte-Carlo simulation could predict remaining life for exposed CCU reactor and FPU column materials with 99\% confidence level. Based on accelerated creep rupture tests, service exposed CCU reactor and FPU column materials have balance lives of 2.4 and 4,78 years respectively. The distillation column material can remain in service for at most three years and they should also be replaced for economic and safety reasons. However, the reactor material needs replacement after a maximum service period of one year, as they are not in healthy state of health, in order to avoid plant accident resulting in huge loss of life and material property.

\section{Acknowledgement}

Authors would like to express their sincere thanks to Director, CSIR- NML, Jamshedpur, India, for permitting us to publish this work and to Dr. Arpan Das for his guidance and help in image analysis.
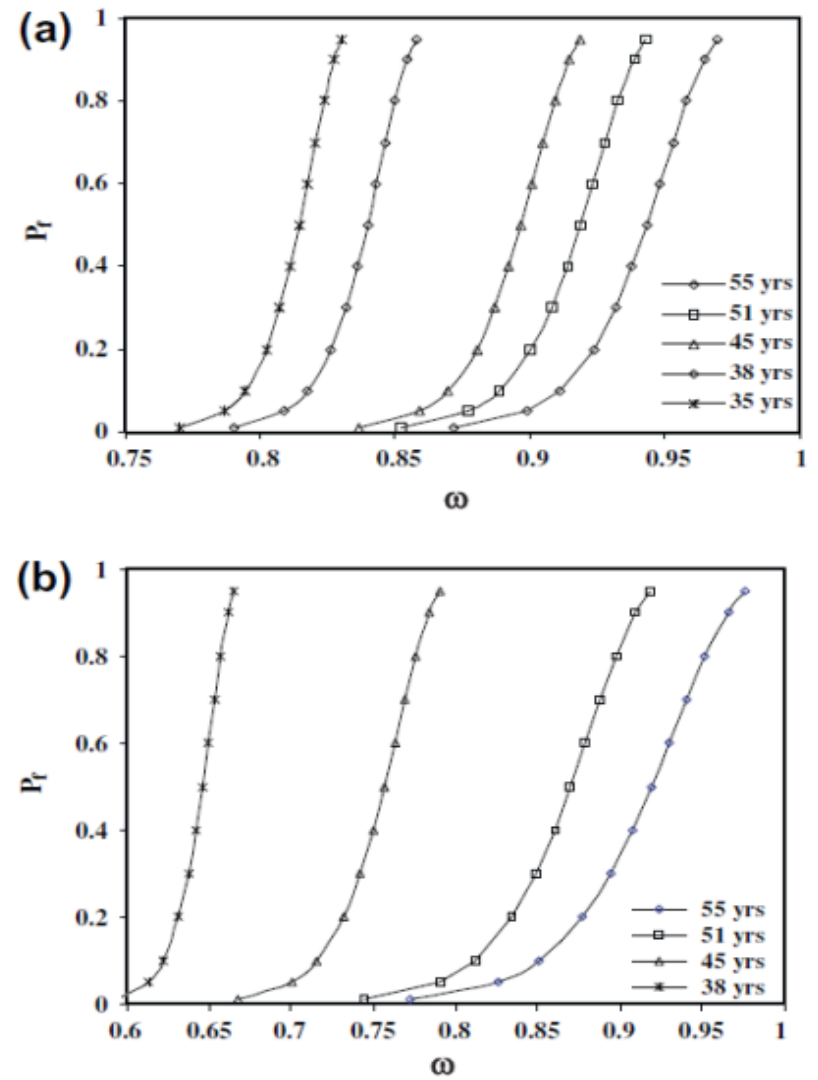

Figure 17: Creep damage distribution for various service exposure: (a) CCU reactor and (b) FPU column material.

\begin{tabular}{|c|c|c|c|c|c|}
\hline $\begin{array}{c}\text { Component } \\
\text { (service exposed) }\end{array}$ & $\begin{array}{c}\text { Temp. } \\
{ }^{\circ} \mathbf{C}\end{array}$ & RL, yrs & $\begin{array}{c}\text { Confidence Interval } \\
\text { (Cl) }\end{array}$ & Lower Cl & $\begin{array}{c}\text { Upper } \\
\mathbf{C l}\end{array}$ \\
\hline CCU reactor & 515 & 2.4 & $99 \%$ & 2.33 & 2.48 \\
\cline { 2 - 5 } & 520 & 0.47 & & 0.42 & 0.52 \\
\hline \multirow{2}{*}{ FPU column } & 515 & 4.78 & $99 \%$ & 4.73 & 4.83 \\
\cline { 2 - 6 } & 520 & 3.34 & & 3.3 & 3.38 \\
\hline
\end{tabular}

Table 3: Remaining life Assessment of 55 years service exposed CCU reactor (ASTM A201 Gr.A) and FPU column (ASTM A285 Gr.C) material with $99 \%$ confidence limit. 
Citation: Ray AK, Roy N, Raj A, Matwa M, Davuluri A, et al. (2014) Uncertainty in Damage Assessment and Remaining Life Prediction of Engineering Materials Used In Petrochemical Industry. J Pet Environ Biotechnol 5: 181. doi:10.4172/2157-7463.1000181

Page 16 of 16

\section{References}

1. Kimura K, Kushima H, Abe F, Yagi K (1997) Inherent creep strength and long term creep strength properties of ferritic steels. Mat Sci Eng A-Struct 234-236: 1079-1082.

2. RayAK, Kumar S, Krishna G, Gunjan M, Goswami B, et al. (2011) Microstructural studies and remnant life assessment of eleven years service exposed reformer tube. Mat Sci Eng A-Struct 529: 102-112.

3. Toft TH, Marsden RA (1963) The structure and properties of $1 \% \mathrm{Cr} 0.5 \%$ Mo steel after twenty years service in CEGB power station. Conference on Structural processes in Creep, London, UK 275.

4. Jahromi JSA, Naghikhani M (2004) Failure Analysis of HP40-Nb Modified Primary Reformer Tube of Ammonia Plant. Iranian Journal of Science and Technology Transaction B 28: 269-271.

5. Ray AK, Sinha SK, Tiwari YN, Swaminathan J, Das G, et al. (2003) Analysis of failed reformer tubes. Eng Fail Anal 10: 351-362.

6. Knowles D, Buchanan K, Kral MV (2009) Condition Assessment Strategies in Centrifugally Cast HP Steam Reformer Tube Alloys. University of Canterbury, Mechanical Engineering, New Zealand.

7. Garafalo F, Whitmore RW, Domis WF, Von Gemmingen F (1961) Creep and Creep-Rupture Relationships in an Austenitic Stainless Steel. Trans Metall AIME 221: 310-319.

8. Weibull W, Sweden SM (1951) A statistical distribution function of wide applicability. J Appl Mech-T ASME 18: 293-297.

9. Johnson RA (2001) Probability and Statistics for Engineers, 6 edn Pearson Educa-tion, Asia.

10. Bogdanoff JL, Krieger W (1978) A New Cumulative Damage Model: Part 2. J Appl Mech 45: 251-257.

11. Ganesan R (2000) A stochastic modelling and analysis methodology for quantification of fatigue damage. Comput Method Appl M 190: 1005-1019.

12. Stewart WJ (1995) Introduction to the Numerical Solution of Markov Chains. Princeton University Press, Princeton USA.

13. Kachanov LM (1958) Time to failure under creep conditions. Izv Anssr Otn 8 : 26-31.

14. Das A, Roy N, Ray AK (2014) Stress induced creep cavity. Mat Sci Eng A-Struct 598: 28-33.

15. Roy N, Guguloth K, Bagui S, Tiwary YN, Ray AK (2013) Damage assessment of service exposed reactor and distillation column materials of a petrochemical industry. Eng Fail Anal 28: 289-301.

16. Yoshiro I, Hitoshi I, Wataru S, Hiroshi I, Nagatoshi O, et al. (2001) Probabilistic life prediction based on field data. European conference on computational mechanics, June 26-29, Krakow, Poland.
18. Rabotnov IN (1969) Creep problems in structural members. North-Holland Pub. Co. Amsterdam

19. Cane BJ (1983) Estimating the remnant creep life of power plant components. High Temp Technol 1: 215-219.

20. Valluri SR (1986) Advances in fracture research : proceedings of the 6th International Conference on Fracture (ICF6), New Delhi, India, 4-10 December 1984. Oxford: Pergamon Press, cop. UK.

21. Dyson BF, Gibbons TB (1987) Tertiary creep in nickel-base superalloys: analysis of experimental data and theoretical synthesis. Acta Metall Mater 35 2355-2369.

22. Leckie FA, Hayhurst DR (1977) Constitutive equations for creep rupture. Acta Metall Mater 25: 1059-1070.

23. Roy N, Bose SC, Ghosh RN (2010) Stochastic aspects of evolution of creep damage in austenitic stainless steel. Mat Sci Eng A-Struct 527: 4810-4817.

24. Roy N, Bagui S, Sahu JK, Ray AK (2013) Creep characterization and damage assessment of long term service exposed P-22 grade of steel. 560: 802-810.

25. Stewart WJ (1994) Introduction to the Numerical Solution of Markov Chains Princeton University Press, Princeton USA.

26. Moss CJ, Barrien P, Walczynski A (2000) Life management of refinery furnace tubing. Int J Pres Ves Pip 77: 105-112.

27. NRIM creep data sheet No. 38A. Data sheets on the elevated temperature properties of centrifugally cast tubes and cast block of $25 \mathrm{Cr} 35 \mathrm{Ni0} .4 \mathrm{C}$ steel for reformer furnaces $(\mathrm{SCH} 24)$.

28. Roy N, Ghosh RN, Bose SC (2010) A stochastic model for evolution of creep damage in engineering materials. T Indian I Metals 63: 665-669.

29. Eggeler G, Brear JM, Cane BJ, Martinez-Ofia R, Baries Fernandez J, et al (1990) Proceedings of 4th International Conference on Creep and Fracture of Engineering Materials and Structures. University College, Swansea.

30. Riedel H (1989) Life prediction methods for constrained grain boundary cavitation. Int J Pres Ves Pip 39: 119-134.

31. Matic Z, Sruk V (2008) The Physics-of-Failure approach in reliability engineering. International Conference on Information Technology Interfaces 23-26 June Dubrovnik, 745 - 750.

32. Ray AK, Tiwari YN, Sinha AN, Sinha Rk, Singh R, et al. (1998) Life prediction of service exposed reactor and distillation column materials used in a petrochemical industry. Eng Fail Anal 5: 289-298.

33. Sivaprasad S, Swaminathan J, Tiwary YN, Roy PK, Singh R (2003) Remaining life assessment of service exposed reactor and distillation column materials of a petrochemical plant. Eng Fail Anal 10: 275-289.

34. Dieter GE (1988) Mechanical Metallurgy. SI Metric edn London, McGraw-Hil USA.

17. Das A (2013) Martensite-Void Interaction. Scripta Mater 68: 514-517. 